\title{
Cellular Cofactors of Lentiviral Integrase: From Target Validation to Drug Discovery
}

\author{
Oliver Taltynov, Belete A. Desimmie, Jonas Demeulemeester, \\ Frauke Christ, and Zeger Debyser
}

The Laboratory for Molecular Virology and Gene Therapy, KU Leuven, Leuven, Flanders, Belgium

Correspondence should be addressed to Zeger Debyser, zeger.debyser@med.kuleuven.be

Received 1 March 2012; Revised 3 June 2012; Accepted 27 June 2012

Academic Editor: Suryaram Gummuluru

Copyright (C) 2012 Oliver Taltynov et al. This is an open access article distributed under the Creative Commons Attribution License, which permits unrestricted use, distribution, and reproduction in any medium, provided the original work is properly cited.

\begin{abstract}
To accomplish their life cycle, lentiviruses make use of host proteins, the so-called cellular cofactors. Interactions between host cell and viral proteins during early stages of lentiviral infection provide attractive new antiviral targets. The insertion of lentiviral cDNA in a host cell chromosome is a step of no return in the replication cycle, after which the host cell becomes a permanent carrier of the viral genome and a producer of lentiviral progeny. Integration is carried out by integrase (IN), an enzyme playing also an important role during nuclear import. Plenty of cellular cofactors of HIV-1 IN have been proposed. To date, the lens epithelium-derived growth factor (LEDGF/p75) is the best studied cofactor of HIV-1 IN. Moreover, small molecules that block the LEDGF/p75-IN interaction have recently been developed for the treatment of HIV infection. The nuclear import factor transportin-SR2 (TRNSR2) has been proposed as another interactor of HIV IN-mediating nuclear import of the virus. Using both proteins as examples, we will describe approaches to be taken to identify and validate novel cofactors as new antiviral targets. Finally, we will highlight recent advances in the design and the development of small-molecule inhibitors binding to the LEDGF/p75-binding pocket in IN (LEDGINs).
\end{abstract}

\section{Introduction: Cofactors of Integration as Potential Antiviral Targets}

Infection with the human immunodeficiency virus type 1 (HIV-1) remains a substantial public health as well as a socioeconomic problem worldwide [1]. Although highly active antiretroviral therapy (HAART) effectively halts HIV replication and profoundly increases survival of patients, it has not been possible yet to achieve a cure. Interruption of HAART typically results in a rebound of virus replication. This is primarily due to the fact that HIV has evolved mechanisms to escape from the continuous immune surveillance in a small pool of latently infected cells that are not susceptible to drug therapy. These latently infected cells reside in reservoirs where the distribution of antiretroviral (ARV) drugs is extremely variable and often lower than the expected maximal inhibitory concentration (for recent reviews see [2$4])$. Moreover, the rapid replication rate and the generation of an extensive genetic diversity fuel the emergence of drugresistant viral strains resulting in treatment failure $[5,6]$. Therefore, there is a continuous demand to search for novel and better ARVs for a better control of the HIV pandemic with the hope to eventually induce permanent remission of the disease.

HIV relies on the host cellular machinery to complete its replication cycle. HIV hijacks several biological processes and protein complexes of the host cell through distinct virushost protein-protein interactions (PPIs) [7, 8]. Since these host-pathogen interactions directly mediate viral replication and disease progression, their specific disruption can provide alternative targets for therapeutic intervention. PPIs represent an attractive group of biologically relevant targets for the development of small-molecule protein-protein interaction inhibitors (SMIPPIs) [9-11]. Since protein-protein interfaces are often based on extended, flat, barely defined, and large hydrophobic surfaces, overcoming binding energy with small 
molecules is hard to achieve. Therefore, obtaining validated starting points for chemical optimization of SMIPPIs has been difficult [11]. Moreover, the applicability of PPIs as therapeutic targets is not only defined by their physicochemical properties but also by the biological properties of the protein-protein interaction and requires meticulous target validation prior to drug discovery.

In recent years, our understanding of the HIV-host interaction has dramatically increased, opening the possibility for the discovery of novel classes of therapeutics [8, 12-14]. Not surprisingly, there are numerous interactions between HIV and cellular proteins involved in all stages of virus replication [8]. In principle, any distinct interaction between virus-encoded proteins and host cofactors has the potential to be a target for drug design. The CCR5 antagonist, maraviroc, was approved as the first ARV targeting a host factor [15]. Maraviroc binds to the CCR5 coreceptor on the surface of cells and prevents interaction with the gp120 envelope protein of the virus [16]. Successful targeting of host-virus PPIs demonstrates that HIV-1 therapeutic drug targets are not limited to virus-encoded enzymes and that understanding of the virus-host interactome can be the basis for future HIV therapeutics [17-20]. In theory, this antiviral strategy is expected to make it more difficult for the virus to develop resistance. Since the host factor is genetically conserved in a biologically relevant host-virus interaction, resistance is less likely to occur increasing the clinical potential of these drugs. Alternatively, drug-induced mutations at a conserved interface may reduce viral fitness [21].

In recent years, HIV-1 integrase (IN) joined the selection of important therapeutic targets to treat HIV infection (for a review see [22]). The enzyme orchestrates the insertion of the viral DNA into the host chromatin [23, 24]. HIV IN is a $32-\mathrm{kDa}$ protein containing 3 canonical structural domains connected by flexible linkers: the N-terminal (NTD, residues 1-50), the catalytic core (CCD, residues 51-212), and the C-terminal domain (CTD, 213-270) (Figure 1(a)). All 3 domains are required for $3^{\prime}$ processing and DNA strand transfer. The solution structure of the N-terminal HHCC domain revealed a three-helix bundle stabilized by zinc [25]. The central catalytic core domain contains the DD(35)E motif conserved among retroviruses and retrotransposons. D64, D116, E152 residues coordinate $2 \mathrm{Mg}^{2+}$ ions necessary for catalysis [26]. The C-terminal domain has a SH3-like fold [27]. Full-length HIV-1 IN is a multimeric enzyme and forms stable tetramers in solution [28].

Despite the recent release of the crystal structure of full-length IN of the prototype foamy virus (PFV) [29], we still lack a crystal structure of full-length HIV-1 IN. The main obstacle for structural studies of HIV IN is its propensity to aggregate. The published two-domain crystal structures of HIV-1 IN (comprising the N-terminal and the catalytic core or the catalytic core and the C-terminal domain) $[30,31]$ as well as the crystal and NMR structures of individual domains (for review see [32]) represent valuable, but incomplete information on the functional structure of the HIV intasome. HIV integrase was the last HIV enzyme to be effectively targeted with small molecules. Reasons were

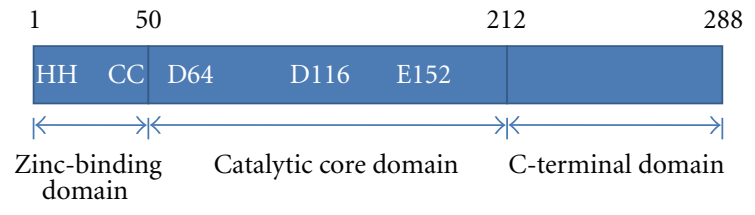

(a)

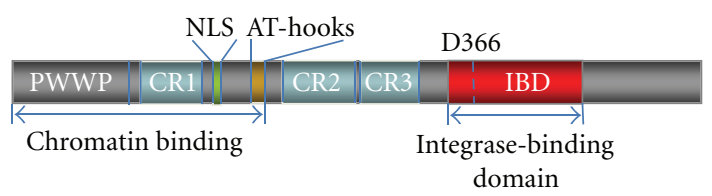

(b)

Figure 1: Domain organization of HIV-1 IN and LEDGF/p75. (a) HIV-1 IN is composed of an N-terminal domain (NTD), a catalytic core domain (CCD), and a C-terminal domain (CTD). The CCD contains the catalytically essential DD(35)E motif and the hot spots for interaction with the IBD in LEDGF/p75. The Asp and Glu residues of the CCD coordinate one or two $\mathrm{Mg}^{2+}$ ions and are involved in $3^{\prime}$ processing and DNA strand-transfer activities. (b) LEDGF/p75 has several structural motifs involved in chromatin tethering and protein-protein interactions. The PWWP domain, the charged regions (CRs), and AT-hooks are involved in chromatin binding. The C-terminus contains the well-characterized IN binding domain (IBD) and acts as a protein interaction playground. Asp residue 366 critical for HIV-1 IN binding is indicated.

the lack of homologous disease targets, as opposed to wellstudied DNA polymerases and aspartyl proteases and the absence of a crystal structure. Indeed, nowadays structural information is playing a central role in successful drug development. HIV protease (PR) was already recognized as a target in the early nineties [33], and soon after the first crystal structure of HIV-1 PR was published [34]. Publication of the structure of HIV-1 PR complexed with the inhibitor MVT101 preceded only by six years the approval of the first PR inhibitor as an anti-HIV drug $[35,36]$.

After completion of reverse transcription, the so-called preintegration complex (PIC) is formed. Along with viral cDNA and IN, the PIC contains viral reverse transcriptase (RT), nucleocapsid (NC), matrix (MA), and Vpr. RT and $\mathrm{NC}$ are involved in the synthesis of viral cDNA, while MA and Vpr may affect nuclear import of the PIC. The PIC also contains host cell proteins, and nuclear import is mediated by the interaction with transport factors and nucleoporins. In the nucleus, HIV IN catalyzes the stable insertion of the viral cDNA into a host chromosome.

The recent success in the application of structure-based rational drug design in the discovery and development of allosteric HIV-1 integrase (IN) inhibitors, the LEDGINs [37], was possible due to 7 years of intensive basic research on the cofactor lens epithelium-derived growth factor/p75 (LEDGF/p75). LEDGINs inhibit the interaction between LEDGF/p75 and HIV-1 IN and will be used as an example to discuss approaches, challenges, and future perspectives of SMIPPIIs. 


\section{Identification and Validation of Cofactors as Novel Antiviral Targets}

Purified proteins from diverse sources could rescue the intermolecular integration activity of retroviral PICs isolated from infected cells and salt-stripped of associated host factors. This observation opened a new field in retrovirology focused on the so-called cellular cofactors of retroviral integration (for review see [38]). Farnet and Bushman noticed that a factor important for integration activity in vitro was removed upon gel filtration of HIV-1 PICs in the presence of high salt [39]. The activity could be restored by addition of protein extracts from uninfected human SupT1 cells. The factor was identified as the highmobility-group chromosomal protein A1 (HMGA1, HMG $\mathrm{I}(\mathrm{Y})$ protein) [39]. HMGA1 is a nonhistone DNA-binding protein involved in the regulation of inducible gene transcription and microRNA expression [40] in both benign and malignant neoplasias [41]. The same method led to discovery of another cellular cofactor of HIV, barrier-toautointegration factor (BAF) [42]. By combining antibodies against known viral and cellular PIC components (MA, Vpr, Ku-80) with anti-BAF antibodies, Lin and Engelman proved that human BAF is a component of PIC [43]. Their functional coimmunoprecipitation strategy was based on examining different fractions obtained from HIV-1-infected C8166 T-cells for the presence of integration activity, viral IN and endogenous BAF [43]. Although BAF was suggested to protect retroviral DNA from autointegration and also to promote the association of PICs with target DNA [44], knockdown of BAF by siRNA in HeLaP4 cells did not affect HIV-1 replication [45]. Validation of the role of cellular cofactors in lentiviral infection, thus, requires multiple independent experimental approaches.

The initial discoveries of HMGA1 and BAF were not the result of a systematic search for cellular cofactors of lentiviral integration. The increasing interest in the interactomics of HIV integration and replication has resulted in algorithms for the identification and proper validation of cofactors (Figure 2). Discovery of novel HIV-1 cofactors as potential antiviral targets can be accomplished by different techniques and is often based on the search for specific and direct protein interaction partners by yeast two-hybrid (Y2H) screen or high-throughput coimmunoprecipitation (co-IP) followed by mass spectroscopy. Alternatively, full-genome RNA interference (RNAi) screens can be used to identify genes/proteins involved in HIV integration/replication.

Physical protein-protein interactions between viral protein and cofactor ( $\mathrm{Y} 2 \mathrm{H}$ and co-IP) need validation in a phenotypic assay. After specific RNAi-mediated depletion of the specific host factor, the impact on HIV replication is determined. If depletion of the candidate cofactor, verified by western blotting and RT qPCR, has no deleterious effect on HIV replication, the cofactor can be dismissed as an important cofactor of HIV replication. If depletion results in a stimulation of HIV replication, the binding partner may represent a restriction factor. In parallel, colocalization of viral protein (IN) and host protein in the cell can be verified by microscopy. Phenotypic assays measure single and multiple rounds of infection in both laboratory immortalized cell lines (e.g., HeLaP4) and primary CD4+ $\mathrm{T}$ cells and macrophages. In our expertise, multiple round replication represents the best assay system to validate cofactors. Use of multiple siRNAs targeting the same cofactor and back-complementation with siRNA-resistant cofactor encoding plasmids should avoid offtarget effects. Growth curves of cells depleted of cofactor should reveal major toxicity effects. An alternative method which can be also conveniently combined with RNAi to validate a cellular cofactor as a target for antiviral drug development is the use of dominant negative mutants, originally successfully exploited for interference with functions of viral proteins [46-48]. Overexpression of the integrase-binding domain (IBD) of LEDGF/p75, for example, blocks HIV-1 replication which was instrumental in studying the role of LEDGF/p75 in the HIV-1 life cycle $[49,50]$.

In case of discovery through a siRNA screen, co-IP or pull down experiments should be carried out to investigate the direct physical interaction between cofactor and viral protein. Quantitative PCR (qPCR) analysis of the different HIV DNA species (reverse transcripts, 2-LTR circles, integrants) in cells depleted for the cofactor may reveal the replication block hinting to the potential interacting viral protein (RT, IN,...$)$. However, the expertise with siRNA screens so far has taught us that cellular pathways rather than specific PPIs are highlighted by this approach [51]. The recent efforts to use high-throughput co-IP and MS to unravel the HIV interactome should reveal more specific HIV cofactors than the siRNA screens [8].

For HIV, efficient strategies for large comprehensive $\mathrm{Y} 2 \mathrm{H}$ screens of different cDNA libraries have been developed [52]. In the primary screen, HIV-1 IN fragments serve as baits. By combination of random and oligo-dT cDNA priming techniques, Rain et al. significantly increased the confidence of the hits by requiring identification of the same positive clone from the two independent cDNA libraries. Confirmation of the specificity of the interactions with HIV IN is done in rebound screens, where hits from the primary screen (potential cellular cofactors) are used as baits against a library of random HIV-1 protein prey fragments. This also allows mapping of respective IN binding domains [52]. By Y2H, IN interactor 1 (INI1)/hSNF5 and transportin-SR2 (TRN-SR2) were identified as IN cofactors [53, 54].

Three RNAi-based whole-genome screens for HIV infection in mammalian cells were reported in 2008 [13, 55, 56], and a meta-analysis of these studies was published in 2009 [57]. Drawbacks of these screens are the use of HeLa or HEK293T cells that are not natural host cells of HIV-1 infection. Later Thys et al. [58] demonstrated that VSVG pseudotyping of HIV may confound interactions with natural host factors during early steps of the replication. Use of mutated or cell-line adapted viruses in the screens can be another source for false negatives and positives. The necessity of proper validation of potential cofactors derived from siRNA screens is underlined by comparison of the results of 2 large siRNA screens performed for HIV. Brass et al. [55] identified 284 genes, whereas Zhou et al. [56] picked 


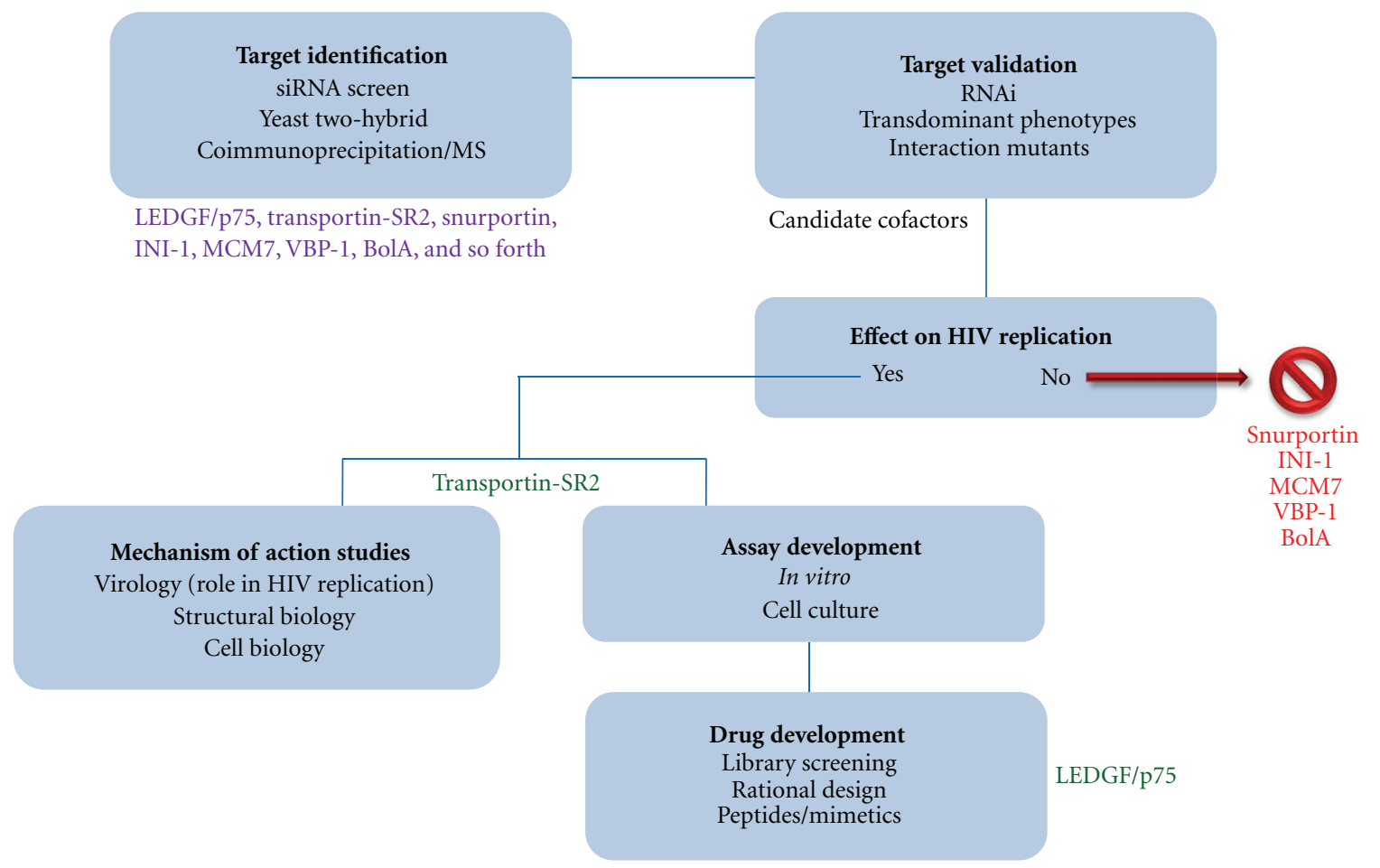

FIGURE 2: Algorithm to identify and validate novel cofactors as antiviral targets with examples of candidate and validated HIV-1 IN cellular cofactors at particular stages of validation. The algorithm was used in the validation of LEDGF/p75 and TRN-SR2 as cellular cofactors of HIV-1 IN and in validating LEDGF/p75 as an antiviral target. In case of some candidate cofactors, the experimental intervention verifying affect on HIV replication was accompanied by toxicity. These candidates were excluded from follow-up steps of drug target validation. These proteins can still be involved in the HIV life cycle but were not considered priority targets.

up 232 genes. Only 15 genes overlapped between both studies [56]. LEDGF/p75 was not identified in either of them.

Nuclear import is an important step in lentiviral infection. The classical technique to study nuclear import of cellular proteins with recombinant import factors is based on digitonin-permeabilized cells [59]. The method was also adapted to study nuclear import of snRNA [60] and DNA [61]. This technique is of limited use for the study of lentiviral nuclear import since NLSs of individual viral proteins can be masked within the PIC, and the data obtained for isolated proteins do not need to fit the real situation during viral infection. There are now better approaches available for studies of lentiviral nuclear import (and early postentry steps in general) based on advances in fluorescence microscopy: real-time in vivo tracking [62-64] and the socalled PIC import assay [54, 65]. The PIC import assay is based on fluorescently labeled viral particles containing IN fused to eGFP (HIV-IN-eGFP) trans-incorporated in the particle through a fusion with HIV-1 Vpr [66].

After validation of the interaction between host factor and viral protein, drug discovery can be initiated, facilitated by high throughput screening (HTS) and high-content screening (HCS) technologies developed since the 1990s, as for example, amplified luminescent proximity homogeneous assay (AlphaScreen) technology, high-throughput FLIM for protein-protein interaction screening, enhanced chemiluminescence, fluorometric microvolume assay technology
(FMAT), LeadSeeker, scintillation proximity assays (SPA), and so forth. These screening technologies allow screens to be performed efficiently, cost-effectively, and with low amounts of material. Nowadays there is a trend to move from labeled reporter assays towards label-free assays [67-69]. If structural biology approaches (crystallography, NMR, SAXS, etc.) can reveal the interface of the PPI aided by site-directed mutagenesis to corroborate the hot spots of the interaction, structure-based drug design can be embarked upon. For the discovery of LEDGINs, AlphaScreen technology and structure-based drug design were used.

\section{The Interaction between LEDGF/p75 and HIV-1 IN Is a Novel Anti-HIV Target}

Today, LEDGF/p75 represents the classical example of a viral cofactor validated as druggable target for antiviral therapy. Basic academic research on the role of LEDGF/p75 in HIV infection ultimately led to development of LEDGINs, firstin-class allosteric HIV-1 integrase inhibitors [37].

LEDGF/p75 was originally identified in Leuven in 2002 by coimmunoprecipitation as a binding partner of HIV-1 IN [28]. LEDGF belongs to the hepatoma-derived growth factor (HDGF) family. Together with HDGF-related proteins (HRPs), this family is composed of chromatin-associated proteins. The N-terminal part of these proteins is highly 
conserved and contains a characteristic PWWP (Pro-TrpTrp-Pro) domain [70, 71] (Figure 1(b)). HDGF and its homologues display between $54 \%$ and $78 \%$ sequence identity among the $91 \mathrm{~N}$-terminal amino acids. Because of this similarity the amino-terminal region has been termed Homologue to Amino Terminus of HDGF (HATH region) $[70,71] . \mathrm{LEDGF} / \mathrm{p} 75$ is implicated in the regulation of stress response proteins. There are two splice variants of LEDGF/p75 expressed from the PSIP1 (PC4- and SFRSinteracting protein 1) gene: LEDGF/p75 and p52. They share the same $\mathrm{N}$-terminal 325 amino acid residues, but have different C-termini; 205 amino acid residues in the case of p75 and 8 in the case of p52. LEDGF/p75 (530 amino acid residues) was identified as a binding partner of HIV-1 IN by immunoprecipitation of IN tetramer complexes from nuclear extracts of $293 \mathrm{~T}$ cells expressing IN from a synthetic gene [28]. Colocalization studies with constructs of IN and LEDGF/p75 fused to GFP or HcRed1 revealed that the Nterminal and the central core domains of HIV IN are involved in the interaction with LEDGF/p75 [72]. The IN-binding domain of LEDGF/p75 was mapped to the C-terminal part of the protein and is absent from LEDGF/p52 [72]. RNAimediated knockdown of endogenous LEDGF/p75 expression abolished nuclear/chromosomal localization of IN [72]. This observation led to the hypothesis that LEDGF/p75 is the main chromatin-tethering factor for IN that hence determines integration site selection of Lentivirinae [73-75]. Through the interaction with LEDGF/p75, integration of HIV into the host cell chromatin is preferentially targeted to the body of active genes [74]. A dynamic scan-and-lock mechanism for the chromatin tethering mediated by the LEDGF/p75 PWWP domain was evidenced by a later study of Hendrix et al. [76].

Soon an evolutionary highly conserved protein-binding domain spanning amino acids 347-429 was identified by means of limited proteolysis and deletion mutagenesis [77]. This domain was coined integrase binding domain or IBD (Figure 1(b)). In the HRP family, the IBD is only present in the hepatoma-derived growth factor-related protein 2 (HRP2). In spite of the identification of the interaction between HIV-1 IN and LEDGF/p75, definition of the IBD in LEDGF/p75, a clear phenotype of IN relocalization after LEDGF/p75 knockdown, and the role of LEDGF/p75 in HIV infection remained disputed for some years, especially after one publication dismissing such role [78]. Multiple lines of increasingly solid evidence were reported in subsequent years 2005-2012 (for more extensive reviews see [7, 79, 80]). A role of LEDGF/p75 in integration and replication of HIV-1 was first suggested by the study of mutants of IN identified by $\mathrm{Y} 2 \mathrm{H}$ screening [81]. A single mutation in IN, Q168A, disrupted the interaction with LEDGF/p75 without major effect on the catalytic activity in vitro. Viruses containing IN-Q168A were defective for replication and the replication block was mapped to the integration step using qPCR. Simultaneously, it was proven that LEDGF/p75 is not required for active nuclear import of the HIV PIC [81]. Using transient and stable knockdown of LEDGF/p75, Vandekerckhove et al. were first to demonstrate a close correlation between LEDGF/p75 levels and extent of HIV integration and replication [82]. Back-complementation of LEDGF/p75 restored viral replication to nearly wild-type levels [82].

In 2005, the solution structure of the IBD of LEDGF/p75 was published [83] and amino acid residues essential for the interaction with HIV-1 IN were identified: Ile365, Asp366, Phe406, and Val408. The IBD is a compact right-handed bundle composed of five $\alpha$-helices. Residues essential for the interaction with IN are localized in the interhelical loop regions of the structure. The crystal structure of the IBD in complex with a dimeric CCD of IN was a major advance in defining the structural properties of the IBD-CCD interface [84]. The LEDGF/p75 binding pocket in IN is formed at the dimeric interface of the CCD of IN. The structure was confirmed by mutagenesis studies of Busschots et al. [85]. Two regions of the IN CCD dimer were identified to be involved in the interaction with LEDGF/p75: one centers around residues Trp131 and Trp132 while the second extends from Ile161 up to Glu170 [85].

In 2006, it was demonstrated that stable overexpression of the IBD reduces HIV replication 100-fold [49]. By competing with endogenous LEDGF/p75 for IN binding, IBD fused to eGFP was able to block HIV-1 replication at the integration step [49]. This result provided proof of concept that the HIV-1 IN/LEDGF/p75 interaction constitutes a novel target for antiviral therapy. Serial passaging of the virus in IBD overexpressing cells yielded a resistant virus with IN mutations at positions 128 and 170 , located at both sides of the LEDGF/p75 binding pocket [21]. Al-Mawsawi et al. subsequently showed that a LEDGF/p75-derived oligopeptide containing the IN interacting residues Ile355 and Asp366 blocked interaction between LEDGF/p75 and IN [86]. Even though peptides and natural products have been shown to modulate PPIs in several therapeutic areas, their physicochemical properties make them less amenable for drug development [9]. Therefore, small molecule inhibitors that bind to the LEDGF/p75 binding pocket in HIV-1 IN were proposed as novel therapeutic strategy [17]. Du et al. [87] reported that a benzoic acid derivative, D77, allegedly disrupted the LEDGF/p75-IN interaction and inhibited HIV replication, albeit with cellular toxicity. Subsequently, structure-based rational drug design resulted in the identification of small molecules (CHIBA-3002 and its analogs) that reduce LEDGF/p75-IN interaction [88]. However, the first potent and selective inhibitors of HIV replication that act by disrupting LEDGF/p75-IN interaction were reported in 2010. We coined the class of small molecule inhibitors that bind to the LEDGF/p75 binding pocket in HIV-1 IN as LEDGINs. The first molecules of this class, quinolinylacetic acid derivatives, were discovered by rational drug design [37]. The reported LEDGINs have potent antiviral activity and are now in advanced preclinical development.

From the drug discovery point of view, the interactions of LEDGF/p75 with other cellular proteins are of importance. Perturbation of these interactions while targeting LEDGF/p75-IN interaction could potentially deregulate the normal cellular role of LEDGF/p75 and lead to cellular toxicity. By $\mathrm{Y} 2 \mathrm{H}$ screens with the C-terminal domain (aa 341-507) of LEDGF/p75 as the bait, JPO2 and pogZ were 
identified as LEDGF/p75 binding partners and their interactions were extensively characterized $[89,90]$. Maertens et al. demonstrated that interaction of JPO2 with LEDGF/p75 is mediated by LEDGF/p75 IBD, and recombinant IN competes with JPO2 for binding to LEDGF/p75 in vitro [91]. A positively charged patch on the surface of the IBD structure is involved in an interaction with another LEDGF/p75 binding partner, Cdc7-activator of S-phase kinase (Cdc7-ASK) [92]. LEDGF/p75 is also a crucial cofactor required for both the oncogenic and tumor suppressor functions of mixed lineage leukaemia protein (MLL)/menin complexes. MLL chimeric oncoproteins in complex with menin are dependent on the association with LEDGF/p75 [93]. Recently, the crystal structure of the ternary complex of menin-Nterminal fragment of MLL1-LEDGFIBD has been published [94].

\section{Rational Design of LEDGF/p75-IN Interaction Inhibitors}

Different approaches have been employed to design and identify small-molecule inhibitors of the LEDGF/p75-IN interaction. These include large-scale screening of chemical libraries [87, 95], computational three-dimensional (3D) database screening of chemical libraries and structure-based de novo design $[37,88]$. High-throughput screening of large libraries of chemicals against a biological target is the prevailing method for the identification of new hit compounds in modern drug discovery. Alternatively, virtual screening is based on a computer-aided survey of large libraries of chemicals that complement targets of known structure and on experimentally testing of a limited set of compounds predicted to bind well. In order to obtain bona fide LEDGF/p75-IN interaction inhibitors, we embarked in 2007 upon structure-based drug design [37]. Drug design is based on a virtual screen of large libraries of small molecules to fit a consensus pharmacophore docked into the region of interest. The consensus pharmacophore consists of chemical groups critical for interaction with amino acid residues or peptide backbones in the proposed drug-binding pocket. In our case the pharmacophore was designed to bind to the LEDGF/p75 binding pocket located at the interface of a dimer of the CCD of HIV-1 IN. In principle, any drug discovery project requires design, prioritization, analysis, and interpretation of results of consecutive experiments to ultimately facilitate the development of new therapeutic compounds. The rational drug design work flow used during the discovery and hit-tolead optimization process of LEDGINs was a combination of methods. The in silico screen for LEDGINs integrates a multidisciplinary approach where existing structural bioinformatics and chemoinformatics were employed in combination with a validated target-based PPI assay [37]. Different crystal structures of the HIV-1 CCD [96] and cocrystal structures with the IBD of LEDGF/p75 [84] or ligand [97] bound to the CCD were superpositioned to refine and construct more precisely a consensus pharmacophore model. Most important features in the final predictive pharmacophore model constructed for virtual screening were a "hydrophobic/aromatic" moiety overlapping with Ile365 of the IBD, a "hydrophobic/aromatic" feature overlapping with Leu368 of the IBD, "acceptor" features mimicking the acid functionality of Asp366, and a "hydrophobic/aromatic" feature overlapping with the Lys364 side chain of LEDGF/p75. 200,000 commercially available and structurally diverse compounds were filtered using the established 3D-pharmacophore query. After stringent sequential scoring and filtering of the initial libraries, 25 promising molecules with the best scoring were ordered for biological evaluation in a bead-based in vitro LEDGF/p75-HIV-1 IN protein-protein interaction assay in the AlphaScreen format. AlphaScreen is a beadbased medium throughput assay optimized to measure the interaction between LEDGF/p75 and HIV-1 IN [37, 89, 95]. Hits emerging from the screening were optimized by reiterative chemical refining and biological profiling in AlphaScreen and in a cell-based antiviral assay, MTT/MT4. Of the 25 molecules retained from the initial screening, four hit molecules inhibited the LEDGF/p75-HIV-1 IN interaction. One of the hit molecules, LEDGIN 1, inhibited the PPI by $36 \%$ at $100 \mu \mathrm{M}$ and served as a starting point for structure-activity relationship (SAR) investigations aimed at the identification of more potent LEDGINs (Figure 3) [37]. Deduced SARs were used to guide synthesis of analogues with enhanced activity. The resulting early lead compounds were then further optimized in an integrated lead optimization strategy while the molecular mechanism of action was investigated in cell culture. Medicinal chemistry optimization, aided by structural information provided by high-resolution cocrystals of LEDGIN 3 soaked into the HIV-1 CCD (Figure 4), generated congeners of LEDGIN 3 (including LEDGIN 6 and 7) with improved biological activity (Figure 3).

Furthermore, LEDGINs did not interfere with the interaction between LEDGF/p75 and its cellular binding partners JPO2 or pogZ, conforming their specificity. Of note, Hou et al. [95] identified several compounds inhibiting the LEDGF/p75-IN interaction through high-throughput screening of a compound library of more than 700,000 small molecules with AlphaScreen. However, the quinolinylacetic acid derivatives are the first examples of potent and specific inhibitors of HIV-1 replication which have been extensively evaluated for their therapeutic potential and mechanism of action in cell-based antiviral assays (including in primary cells) [37].

\section{LEDGINs as Therapeutics}

A critical evaluation of the mechanism of action and therapeutic potential of LEDGINs requires investigation of different drug characteristics: (a) a high binding affinity and specificity to HIV-1 IN, (b) potent and broad spectrum antiHIV activities in cell-based antiviral assays, (c) lack of toxicity, and (d) a optimal pharmacokinetic (PK) and pharmacodynamic (PD) profile allowing a once a day administration in patients. We could demonstrate that inhibition of the LEDGF/p75-HIV-1 IN interaction by LEDGINs blocks HIV 
<smiles>Cn1c(=O)c(/C(=N/c2ccccc2)c2nnn[nH]2)c(O)c2ccccc21</smiles>

(1)<smiles>CCCC(C(=O)O)c1c(-c2ccccc2)c2cc(Cl)ccc2n(CCC)c1=O</smiles>

$(4)$<smiles>CCOc1ccc(N=C(c2nnn[nH]2)c2c(O)c3ccccc3n(C)c2=O)cc1</smiles>

(2)<smiles>C=CCC(C(=O)O)c1c(-c2ccccc2)c2cc(Cl)ccc2[nH]c1=O</smiles>

(5)<smiles>O=C(O)Cc1c(-c2ccccc2)c2cc(Cl)ccc2[nH]c1=O</smiles>

(3)<smiles>CCCC(C(=O)O)c1c(C)nc2ccc(Cl)cc2c1-c1ccccc1</smiles>

(6)<smiles>CCCC(C(=O)O)c1c(C)nc2sc(C)cc2c1-c1ccccc1</smiles>

(7)

FIgure 3: Chemical structures of the LEDGINs. Of the 25 molecules tested in AlphaScreen, compound 1 was identified as the initial hit with in vitro activity. Compounds $\mathbf{2}$ and 3 are commercial congeners of $\mathbf{1}$. Compounds $\mathbf{4}-\mathbf{7}$ are newly synthesized compounds with improved in vitro and in vivo activities. After serial rounds of optimization by medicinal chemistry, the early lead compounds 6 and 7 were identified with potent and selective anti-HIV activity. Compound 7 has submicromolar antiviral activity [37].

integration [37]. Integration inhibitors are characterized by a typical pattern of viral DNA species as measured by qPCR. 2-LTR circles are the dead-end byproduct of nonintegrated viral DNA; their number is increased upon integration block if upstream steps are not hampered [98]. We showed that both the classical integrase strand transfer inhibitor (INSTI) raltegravir and LEDGINs reduce the number of integrated proviral DNA and increase the number of 2-LTR circles without effect on reverse transcription. Resistance selection in cell culture against a new class of antiviral agents ultimately corroborates the antiviral target. By serial passaging of HIV1 in increasing concentrations of LEDGIN $\mathbf{6}$, we selected a resistant strain with the A128T substitution in IN. The A128 residue is a hot spot of the IN-LEDGF/p75 interface and was included in the predictive pharmacophore model for the virtual screen. The resistance mutation, thus, corroborates the specificity of LEDGINs. The A128T mutation in integrase is not associated with resistance to INSTIs and LEDGINs lack cross-resistance with other ARV classes corroborating their novel mode of action. Of note, it was recently shown that LEDGINs can also block the interaction between HRP-2 and HIV IN in the absence of LEDGF/p75 [99].

In conclusion, there are obvious advantages of drugs targeting LEDGF/p75-IN interaction. LEDGINs show a pathway of resistance development that is different from that of the INSTIs and lacks cross-resistance with ARV in the 


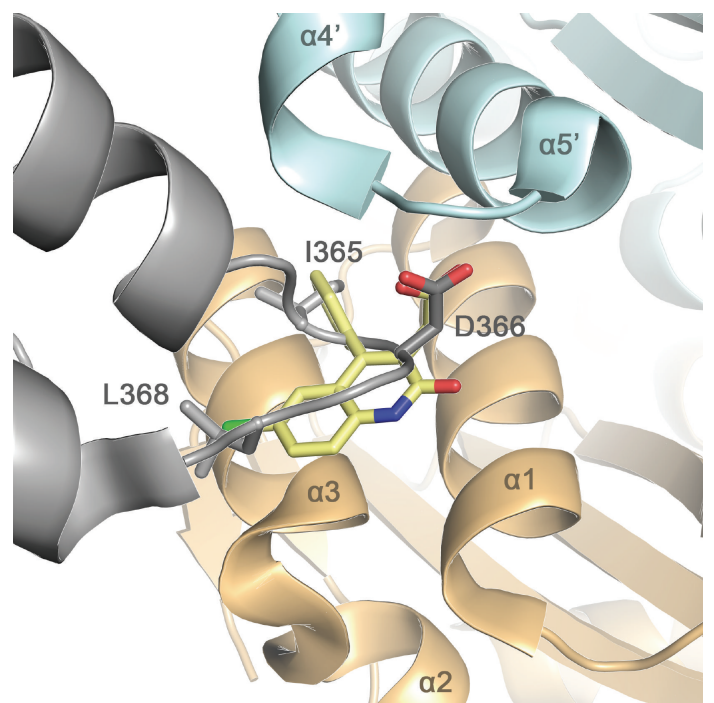

FIgURE 4: Cartoon representation of the LEDGIN 3 (yellow) superimposed with the LEDGF/p75 IBD (gray) in the pocket at the interface of the IN CCD dimer (light blue and orange). LEDGINs bind to the LEDGF/p75 binding pocket in HIV-1 IN and thereby block the interaction of the IBD of LEDGF/p75 with the dimer of the CCD, thereby interfering with tethering of the HIV-1 PIC to the host cell chromatin.

clinic [100]. Discovery of LEDGINs is a good example of structure-based rational drug design targeting a well-defined and biologically relevant PPI.

\section{HIV Integrase Cofactors and Nuclear Import}

To accomplish their life cycle, retroviruses need to integrate their genetic material into the host DNA in the nucleus. For this purpose, retroviruses developed distinct strategies to overcome the nuclear membrane barrier. Gammaretroviruses such as murine leukemia virus (MLV), for example, cannot pass nuclear pore complexes and only integrate during mitosis after breakdown of the nuclear membrane [101]. Lentiviruses such as HIV in contrast are able to infect both dividing and nondividing cells [102, 103]. Many factors, both from viral and host cell origin, have been suggested to take part in the nuclear import of the lentiviral preintegration complex (PIC) (for reviews see $[104,105]$ ). Nuclear import is a bottleneck in lentiviral infection, and cellular cofactors of this process are attractive targets for anti-HIV therapy. Although recent studies shed light on lentiviral PIC transport to the nucleus, general consensus on the importance of particular viral and cellular players still has to be established. From the viral proteins present in the PIC IN, matrix (MA) and viral protein $\mathrm{R}(\mathrm{Vpr})$ were suggested to affect nuclear import, and several nuclear localization signals (NLSs) were identified in these proteins (for review see [105]). A cis-acting central polypurine tract (cPPT), a sequence present almost exclusively in the lentivirus genus and used for initiation of plus-strand synthesis, may as well affect the efficiency of nuclear import [106-108]. However, HIV with mutations in each of the NLSs still remained infectious in nondividing cells [109]. Yamashita and Emerman, using HIV chimeric viruses in which the entire IN sequence was replaced by that of MLV, and all the other NLSs in MA, Vpr, and cPPT were eliminated, demonstrated that neither of these NLSs is essential for the ability of HIV to infect nondividing cells [110]. Despite the fact that none of the above-mentioned viral elements appears absolutely required for nuclear import, a major effect of the cPPT on the kinetics of viral DNA entry into the nucleus was demonstrated $[108,111,112]$. After excluding a role for the previously reported viral NLSs in lentiviral nuclear import, two major explanations for the cell cycle independence of lentiviral nuclear entry prevail. Limited uncoating of the gammaretroviral capsid may interfere with importinmediated transport through the nucleopore, whereas timely disassembly of the lentiviral capsid may allow interaction with importin(s). Alternatively, interaction with components of the nuclear import machinery may be restricted to proteins present in the lentiviral PIC. For a discussion on the impact of the lentiviral capsid on nuclear import, we refer to [113-115].

Several nuclear import factors and nucleoporins (Nups) have been implicated in HIV nuclear import: importin $\alpha 1^{*}$ [116-119], importin $\alpha 3^{*}[120,121]$, importin $7^{*}[122,123]$, Nup153* [13, 55, 124-127], Nup62* [128], Nup54 [129], Nup85 [55, 125], Nup98 [13, 130-132], Nup107 [55, 125], Nup133 [55, 125], Nup155 [130], Nup160 [55, 125], Nup210 [130], Nup214 [13], and Nup358/RanBP2 [13, 55, 115, 125, $133,134]$ (proteins with * were shown to interact with IN).

Importin $\alpha 1 /$ Rch 1 was the first karyopherin shown to interact with HIV-1 IN [117]. The study was initiated by the observation that the growth defect of a HIV-1 $\mathrm{MA} / \mathrm{Vpr}$ double deletion mutant in terminally differentiated macrophages was masked at high MOI. These data pointed to an activity that can substitute for MA and $\mathrm{Vpr}$ in the nuclear import of the HIV-1 PIC. Authors showed that HIV-1 IN is a karyophilic protein, detected IN-Imp $\alpha 1$ interaction, and defined two NLSs (one around positions 186-189 $\left(\mathrm{KRK}^{188}\right)$ and one encompassing residues 211219 (KELQKQITK $\left.{ }^{219}\right)$ ) in the C-terminal region of HIV$1 \mathrm{IN}$ as responsible for the interaction [117]. The INImp $\alpha 1$ interaction was initially confirmed by in vitro binding studies $[119,135]$, but questioned later by work of Ao et al. [123]. The Imp $\alpha$ family contains 6 isoforms grouped into 3 subfamilies with a primary sequence identity between 50 and $85 \%$ [136]. In vitro studies suggest that various isoforms can recognize the same NLS-containing proteins, although with different binding efficiency [120]. Therefore, Ao et al. [120] investigated the contributions of the different Imp $\alpha$ isoforms to HIV-1 replication. Via shRNA, mediated knockdown Imp $\alpha 3$ was shown to be required for efficient HIV infection of HeLaP4 cells, T cells, and primary macrophages. qPCR analysis revealed that Imp $\alpha 3$-knockdown resulted in a significantly reduced level of 2-LTR circles, suggesting a role in HIV nuclear import. By immunoprecipitation, the HIV1 IN-Imp $\alpha 3$ interaction was attributed to the C-terminal domain (CTD aa 250-270) of IN. Imp $\alpha 1$ and Imp $\alpha 5$ also affected HIV infection [120]. The importance of importin $\alpha$ isoforms for HIV nuclear import was questioned by 
work of Depienne et al. [137] who studied nuclear import in digitonin-permeabilized HeLa cells. According to these authors, nuclear accumulation of IN (as a protein) does not involve karyopherins $\alpha, \beta 1$, and $\beta 2$-mediated pathways and is also independent of GTP hydrolysis and Ran [137]. Here, we raise again the question whether nuclear import of IN is relevant for the nuclear entry of the HIV PIC. Importin 7 (Imp7) has also been implicated in HIV-1 nuclear import. Originally, it was proposed as a HIV-1 nuclear import factor by Fassati et al. based on nuclear import of purified HIV-1 reverse transcription complexes in digitoninpermeabilized HeLa cells and primary human macrophages [122]. However, when Zielske and Stevenson depleted Imp7 by $80-95 \%$ in primary macrophages and HeLa cells using RNAi, neither the rate nor the extent of HIV-1 or SIV cDNA synthesis or nuclear translocation was affected [138]. In a direct comparison using coimmunoprecipitation, HIV-1 IN was found to interact with Imp7, but not with Imp $\alpha 1 /$ Rch1 [123]. Finally, the Fassati group admitted that Imp7 is not essential for HIV-1 infection but maximizes nuclear import [139].

In a full-genome siRNA screen, Nup153, Nup214 and Nup358 were found to play a role in the nuclear import and Nup98 in the integration of HIV [13], although detailed validation still had to be performed. Nup153 and Nup358/RanBP2 are the most extensively studied Nups in the context of HIV infection. Nup153 has been shown to interact with HIV-1 IN, and the interaction is mediated by its C-terminal domain rich in FxFG repeats [124]. When added in excess to the semipermeabilized import assay, the C-terminal domain of Nup153 inhibited the nuclear import of HIV-1 IN [124]. Interestingly, codepletion of Nup153 and transportin-SR2 (TRN-SR2) yielded synergistic effects, that outweighed those calculated based on individual knockdowns, indicating potential interdependent roles for these factors during HIV-1 infection [127]. Nups requirement for HIV-1 infection was further studied by Lee et al. [125]. HIV-1 infection was impaired by Nup358/RanBP2, Nup153, or Nup160 knockdown. In contrast, infection by the HIV1 CA N74D mutant (see below) was less dependent on Nup358/RanBP2 and Nup153, suggesting that these proteins interact, directly or indirectly, with CA during infection [125].

Nup62 has been shown to act at several steps during HIV-1 replication. Monette et al. first showed that HIV-1 replication markedly alters the localization of Nup62 and that its expression is linked to the nuclear export of the unspliced viral genomic RNA [140]. Later proteomics and immunogold electron microscopy studies showed that HIV-1 infection induces extensive changes in the composition of the nuclear envelope and its associated proteins and identified Nup62 as a component of purified virus [141]. Former observation is particularly important for consideration of the involvement of individual Nups and Nups-interacting partners (like importins) in HIV infection. HIV-1 can via remodeling of the nuclear pore complexes (NPCs) make accessible Nups which facilitate nuclear import and/or integration, and the process of remodeling can have impact not only on late stages of infection (production of the progeny), but also on the mentioned early steps. Encapsidated Nup62 may be required for efficient nuclear import of the PIC in newly infected cells [141].

Nup62 has recently been proposed as a binding partner of HIV-1 IN [128]. GST-tagged IN was able to pull down Nup62. The specificity of the interaction was further proven by co-IPs. Nup62 knockdown in CD4+ T cells and macrophages significantly inhibited HIV-1 infection and by qPCR analysis, the block of the infection was pinpointed to viral integration and in a much lesser extent to the nuclear import step. Subcellular protein fractionation showed that Nup62 binds to chromatin, interacts with HIV-1 IN both in the nuclear and chromatin bound extracts, and knockdown of Nup62 significantly reduced the association of the IN with chromatin causing impaired HIV-1 integration observed also by qPCR. Finally, expression of the C-terminal domain of Nup62 in CD4+ T cells reduced the association of IN with chromatin and did inhibit HIV-1 infection [128].

HIV integration is favored in chromosomal regions rich in active transcription units and associated features such as CpG islands, DNAaseI hypersensitive sites, and high G/C content [142]. Integration site sequencing offers a new view on how HIV-1 uses the host nuclear import machinery to reach its integration sites $[115,134]$. Wild-type HIV-1 in the presence of cyclosporine (Cs), HIV-1 CA mutants deficient for CypA interaction (CA G89V or P90A), and chimeric HIV-1 containing SIVmac CA, all integrate in genomic areas of high gene density/activity. On the contrary, HIV-1 capsid mutants that are less sensitive to TRN-SR2, Nup358 or Nup153 depletion by RNAi (CA N74D or N57A) integrate in genomic areas of low gene density/activity. Both groups of CA mutants were impaired in replication in HeLa cells and human macrophages. In accord with the observed differences in integration pattern, a block of engagement of CypA/Nup358 by mutating the virus CA or by inhibiting cellular CypA with cyclosporine force HIV-1 to use for nuclear import and integration a Nup358/Nup153independent pathway [115].

In 2008, transportin-SR2 (TRN-SR2, TNPO3) was independently identified as a cellular cofactor of HIV-1 replication in two siRNA screens $[13,55]$ and as a HIV-1 IN binding partner by $\mathrm{Y} 2 \mathrm{H}$ screening [54]. Although its exact role in HIV-1 infection has not been fully clarified, several independent studies confirmed TRN-SR2 as a genuine cellular cofactor to the extent that it is now being used as a positive control in HIV-1 interaction studies [143].

\section{Transportin-SR2 as a Cofactor of HIV Nuclear Import.}

TRN-SR2 belongs to the importin- $\beta$ superfamily of karyopherins [144]. The protein has 975 amino acid residues and is composed of $\alpha$-helical HEAT repeats. TRN-SR2 is known to import essential splicing factors, the serine/arginine-rich proteins (SR proteins), to the nucleus and is, therefore, involved in the regulation of both constitutive and regulated precursor mRNA splicing. The recognition of the SRproteins by TRN-SR2 relies on the conserved RS-domain 


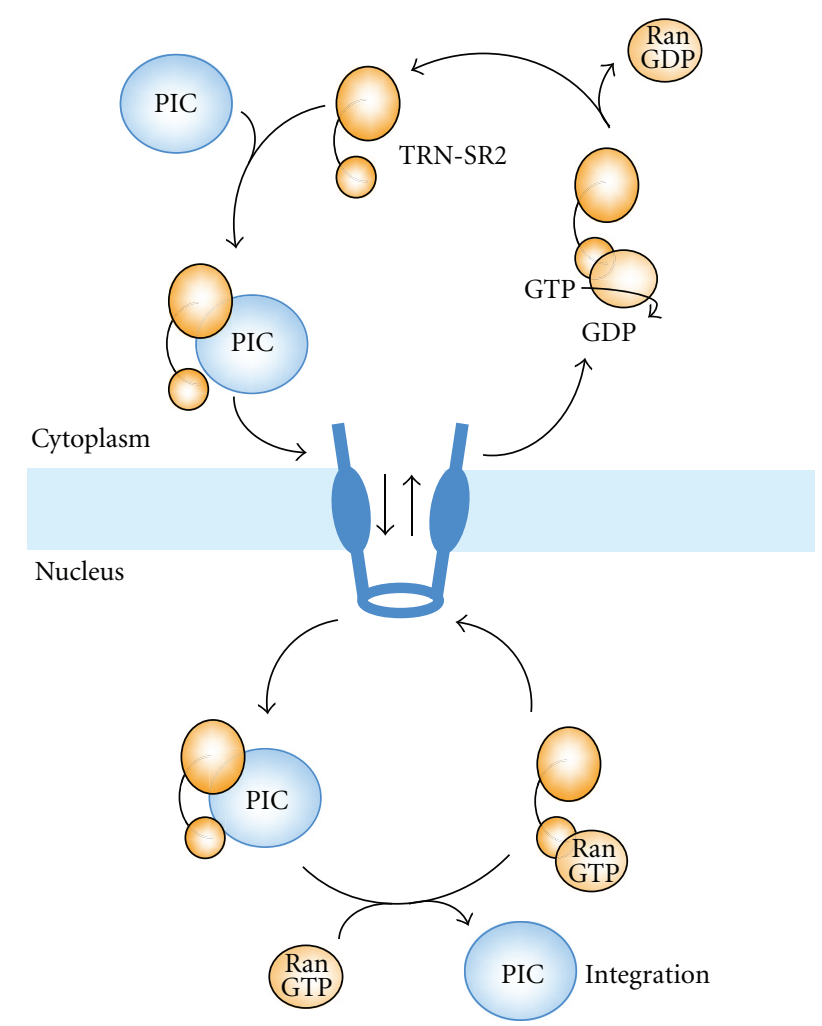

FIgURE 5: Scheme of nuclear import of the PIC and TRN-SR2 recycling.

and requires phosphorylation [144-146] although TRNSR2 is known to import as well proteins not belonging to the SR protein family $[147,148]$. The RS domain of SR proteins serves both as an NLS and a subnuclear localization signal $[149,150]$. A TRN-SR2 mutant deficient in Ran binding colocalized with SR proteins in nuclear speckles [146]. TRN-SR2 binds its cargo in the cytoplasm and via its interaction with the nuclear pore proteins translocates with cargo to the nucleus (Figure 5). The import is linked to the RanGTP/RanGDP cycle. The small protein Ran GTPase is a member of the Ras protein superfamily and the motor of nuclear protein import. Interaction between Ran and karyopherins is modulated by the state of the bound nucleotide (GTP or GDP). In the nucleus, RanGTP binds to TRN-SR2, displaces the cargo, and then shuttles together with TRN-SR2 to the cytoplasm, where GTP is hydrolyzed to GDP. In the GDP-bound state, Ran dissociates from TRN-SR2 enabling a new round of nuclear import [151]. TRN-SR2 has been shown to interact with Nup62 or its associated complex [146]. Of note, Nup62 is translocated to the cytoplasm and encapsidated into HIV-1 virions during HIV-1 infection [140, 141].

ASF/SF2 has been proven to affect the splicing pattern of HIV RNA transcripts $[152,153]$. The nuclear import of this splicing factor is mediated by TRN-SR2 and this was the first indication of a possible involvement of TRN-SR2, in HIV replication. TRN-SR2 was identified as a cellular cofactor of HIV-1 in the RNAi genome-wide screens [13, 55], but not in the Zhou screen [56]. TRN-SR2 knockdown had little or no effect on murine leukemia virus (MLV) transduction $[54,55]$. Interaction of TRN-SR2 with HIV$1 \mathrm{IN}$ was originally detected in a $\mathrm{Y} 2 \mathrm{H}$ screen of a random primed CEMC7 cDNA library with HIV-YU2 IN as bait [54]. Exclusivity of the interaction with viral IN was verified in a reverse screen against a library of HIV genome DNA fragments. The specificity of the interaction of HIV-1 IN with TRN-SR2 was confirmed in pulldown assays [54]. SiRNA-mediated knockdown of TRN-SR2 resulted in a 6fold inhibition of HIV replication in HeLaP4 cells [54]. TRNSR2 specific shRNA reduced infectivity of both HIV-1 ( 8to 10-fold) and SIVmac ( 20-fold) [54, 115]. Interestingly, IN inhibitor-resistant viruses are still susceptible to TRNSR2 knockdown [54]. By real-time qPCR, the block in HIV replication was mapped to a moment after reverse transcription and prior to integration, which coincides with nuclear import [54]. The import assay with IN-eGFP labeled virus [65] was used to corroborate the role of TRN-SR2 in HIV nuclear import [54]. After depletion of TRN-SR2 using red fluorescent siRNA, the treated cells were infected by HIV-IN-eGFP. In cells positive for the red fluorescent label, the numbers of PICs present in the nucleus versus the cytoplasm were counted. The nuclear/cytoplasmic ratio of PICs dropped 5-fold in the TRN-SR2 depleted cells [54].

A possible role of lentiviral capsid in TRN-SR2-mediated nuclear import was suggested by the finding that both a chimeric HIV virus, carrying MLV capsid (CA), MA and 12 proteins, and a HIV-1 strain, carrying the CA N74D mutant, apparently were insensitive to TRN-SR2 knockdown $[58,125,154,155]$. Authors concluded that the viral capsid and not IN determines TRN-SR2 dependency of HIV infection. One should be careful with interpretation of some data. Some studies $[154,156]$ were done with pseudotyped HIV virus carrying the vesicular stomatitis virus $G$ envelope (VSV-G), known to induce receptormediated endocytosis instead of membrane fusion as a way to enter the cell. Moreover, VSV-G pseudotyped HIV does not engage chemokine coreceptors (CCR5, CXCR4) known to induce signal transduction cascades in the cell [157]. When TRN-SR2 knockdown cells were infected with viruses carrying the wild type HIV-1 envelope, the HIV-1 N74D CA mutant regained sensitivity to TRN-SR2 knockdown [58].

TRN-SR2 is not used to the same extent as a nuclear import factor by all lentiviruses $[58,154,156]$ but a direct correlation between the phenotype in cell culture and the in vitro PPI has not yet been documented. Logue et al. showed that the Drosophila TRN-SR2 can substitute for its human counterpart and defined the cargo-binding domain of TRN-SR2 as required for lentivirus infection [156]. From the IN part of the interaction, IN mutations previously characterized to impair LEDGF/p75 binding (W131A, Q168L) were insufficient to affect nuclear import [158]. Zhou et al. recently proposed a model in which CA along with tRNAs is export cargoes for TRN-SR2 in a RanGTP-dependent way [159]. According to this hypothesis, TRN-SR2 modulates nuclear uncoating of imported PICs by removing any remaining CA proteins and tRNAs blocking the integration step and promotes nuclear export of these 
viral components. The model suggests that efficient HIV1 integration depends on this TRN-SR2 activity [159]. Another study hinted at a role for TRN-SR2 prior to integration. HIV integration site selection was modified by depletion of TRN-SR2 and Nup358/RanBP2 [134]. However, this observation can alternatively be explained by the fact that correct trafficking through the NPC may facilitate the subsequent integration step. Although a clear understanding of HIV nuclear import and on the role of TRN-SR2 requires more experimentation, all data are consistent with a close link between HIV uncoating in the cytoplasm and nuclear import on the one hand, and nuclear import and integration on the other hand.

\section{Conclusions}

This paper highlights the importance of research on cellular cofactors of HIV replication as potential targets for anti-HIV drugs. The interaction between LEDGF/p75 and IN is crucial for HIV replication, and the rational design of LEDGINs as novel antivirals represents an important achievement in translational research. Efficient targeting of host-virus PPIs expands the possible arsenal of targets beyond HIV-encoded enzymes. This novel paradigm can be extended to other viral diseases. Increased understanding of the virus-host interactome can be the basis for plenty of future antivirals. Since PPIs have pivotal roles in virtually all physiological and disease-related intracellular macromolecular complexes, development of SMIPPIs can benefit many therapeutic areas. While the example described here is particularly relevant to the field of virology, applications of SMIPPI technology to other fields will increase as our knowledge on the role of PPIs in human diseases expands.

Since the nuclear import of PICs still represents a black box in our knowledge of HIV infection and since IN plays an active role at this stage, study of the IN interactome may also shed light on this process. The discovery that the importin TRN-SR2 is a binding partner of IN can provide the lever to open this box. Research on HIV nuclear import not only provides us with insights in basic virology, but also has great potential for drug discovery especially since nuclear import is a bottleneck in HIV replication. There is increasing evidence that lentiviral chromosomal target site selection for integration is linked to nuclear import of PICs. Moreover, proper illumination of the lentiviral route to the nucleus and of the impact on integration site selection will aid the design of safer gene therapy approaches.

\section{Conflict of Interests}

The authors disclose any other conflict of interests.

\section{Acknowledgments}

The described work has been funded by the European Commission (FP6/FP7) through the European Consortia TRIoH (LSHB-CT-2003-503480) and THINC (HEALTHF3-2008-201032), the Flemish IWT (CellCoVir SBO), and
KU Leuven BOF and IOF. Belete A. Desimmie is a DBOF fellow of the KU Leuven, Frauke Christ is an IOF fellow and Jonas Demeulemeester is an FWO fellow. KU Leuven has entered a license agreement with Pfizer for the development of LEDGINs.

\section{References}

[1] UNAIDS, "Report on the global AIDS epidemic. Geneva, UNAIDS,” 2010, http://www.unaids.org/en/Knowledge Centre/HIVData/GlobalReport/2008.

[2] S. Moir, T. W. Chun, and A. S. Fauci, "Pathogenic mechanisms of HIV disease," Annual Review of Pathology, vol. 6, pp. 223-248, 2011.

[3] S. K. Choudhary and D. M. Margolis, "Curing HIV: pharmacologic approaches to target HIV-1 Latency," Annual Review of Pharmacology and Toxicology, vol. 51, pp. 397-418, 2011.

[4] D. M. Margolis, "Eradication therapies for HIV infection: time to begin again," AIDS Research and Human Retroviruses, vol. 27, no. 4, pp. 347-353, 2011.

[5] R. Nájera, E. Delgado, L. Pérez-Alvarez, and M. M. Thomson, "Genetic recombination and its role in the development of the HIV-1 pandemic," AIDS, vol. 16, no. 4, pp. S3-S16, 2002.

[6] A. Rambaut, D. Posada, K. A. Crandall, and E. C. Holmes, "The causes and consequences of HIV evolution," Nature Reviews Genetics, vol. 5, no. 1, pp. 52-61, 2004.

[7] B. Van Maele, K. Busschots, L. Vandekerckhove, F. Christ, and Z. Debyser, "Cellular co-factors of HIV-1 integration," Trends in Biochemical Sciences, vol. 31, no. 2, pp. 98-105, 2006.

[8] S. Jäger, P. Cimermancic, N. Gulbahce et al., "Global landscape of HIV-human protein complexes," Nature, vol. 481, no. 7381, pp. 365-370, 2011.

[9] T. Berg, "Modulation of protein-protein interactions with small organic molecules," Angewandte Chemie, vol. 42, no. 22, pp. 2462-2481, 2003.

[10] J. A. Wells and C. L. McClendon, "Reaching for high-hanging fruit in drug discovery at protein-protein interfaces," Nature, vol. 450, no. 7172, pp. 1001-1009, 2007.

[11] M. R. Arkin and J. A. Wells, "Small-molecule inhibitors of protein-protein interactions: progressing towards the dream," Nature Reviews Drug Discovery, vol. 3, no. 4, pp. 301317, 2004.

[12] E. De Clercq, "HIV life cycle: targets for anti-HIV agents," in HIV-1 Integrase: Mechanism and Inhibitor Design, $\mathrm{N}$. Neamati, Ed., pp. 1-14, John Wiley \& Sons, Hoboken, NJ, USA, 2011.

[13] R. König, Y. Zhou, D. Elleder et al., "Global analysis of host-pathogen interactions that regulate early-stage HIV-1 replication," Cell, vol. 135, no. 1, pp. 49-60, 2008.

[14] L. Houzet and K. T. Jeang, "Genome-Wide screening using RNA interference to study host factors in viral replication and pathogenesis," Experimental Biology and Medicine, vol. 236, no. 8, pp. 962-967, 2011.

[15] P. Dorr, M. Westby, S. Dobbs et al., "Maraviroc (UK427,857 ), a potent, orally bioavailable, and selective smallmolecule inhibitor of chemokine receptor CCR5 with broadspectrum anti-human immunodeficiency virus type 1 activity," Antimicrobial Agents and Chemotherapy, vol. 49, no. 11, pp. 4721-4732, 2005.

[16] S. Sayana and H. Khanlou, "Maraviroc: a new CCR5 antagonist," Expert Review of Anti-Infective Therapy, vol. 7, no. 1, pp. 9-19, 2009. 
[17] K. Busschots, J. De Rijck, F. Christ, and Z. Debyser, "In search of small molecules blocking interactions between HIV proteins and intracellular cofactors," Molecular BioSystems, vol. 5, no. 1, pp. 21-31, 2009.

[18] C. S. Adamson and E. O. Freed, "Novel approaches to inhibiting HIV-1 replication," Antiviral Research, vol. 85, no. 1, pp. 119-141, 2010.

[19] W. C. Greene, Z. Debyser, Y. Ikeda et al., "Novel targets for HIV therapy," Antiviral Research, vol. 80, no. 3, pp. 251-265, 2008.

[20] A. P. Rice and R. E. Sutton, "Targeting protein-protein interactions for HIV therapeutics," Future HIV Therapy, vol. 1, no. 4, pp. 369-385, 2007.

[21] A. Hombrouck, J. De Rijck, J. Hendrix et al., "Virus evolution reveals an exclusive role for LEDGF/p75 in chromosomal tethering of HIV," PLoS Pathogens, vol. 3, no. 3, Article ID e47, 2007.

[22] Y. Luo and M. A. Muesing, "Prospective strategies for targeting HIV-1 integrase function," Future Medicinal Chemistry, vol. 2, no. 7, pp. 1055-1060, 2010.

[23] F. D. Bushman, T. Fujiwara, and R. Craigie, "Retroviral DNA integration directed by HIV integration protein in vitro," Science, vol. 249, no. 4976, pp. 1555-1558, 1990.

[24] O. Delelis, K. Carayon, A. Saib, E. Deprez, and J. F. Mouscadet, "Integrase and integration: biochemical activities of HIV-1 integrase," Retrovirology, vol. 5, article 114, 2008.

[25] A. P. A. M. Eijkelenboom, F. M. I. Van Den Ent, A. Vos et al., "The solution structure of the amino-terminal HHCC domain of HIV-2 integrase: a three-helix bundle stabilized by zinc," Current Biology, vol. 7, no. 10, pp. 739-746, 1997.

[26] L. Haren, B. Ton-Hoang, and M. Chandler, "Integrating DNA: transposases and retroviral integrases," Annual Review of Microbiology, vol. 53, pp. 245-281, 1999.

[27] A. P. A. M. Eijkelenboom, R. A. P. Lutzke, R. Boelens, R. H. A. Plasterk, R. Kaptein, and K. Hard, "The DNA-binding domain of HIV-1 integrase has an SH3-like fold," Nature Structural Biology, vol. 2, no. 9, pp. 807-810, 1995.

[28] P. Cherepanov, G. Maertens, P. Proost et al., "HIV-1 integrase forms stable tetramers and associates with LEDGF/p75 protein in human cells," Journal of Biological Chemistry, vol. 278, no. 1, pp. 372-381, 2003.

[29] S. Hare, S. S. Gupta, E. Valkov, A. Engelman, and P. Cherepanov, "Retroviral intasome assembly and inhibition of DNA strand transfer," Nature, vol. 464, no. 7286, pp. 232$236,2010$.

[30] J. Y. Wang, H. Ling, W. Yang, and R. Craigie, "Structure of a two-domain fragment of HIV-1 integrase: implications for domain organization in the intact protein," EMBO Journal, vol. 20, no. 24, pp. 7333-7343, 2002.

[31] J. C. H. Chen, J. Krucinski, L. J. W. Miercke et al., "Crystal structure of the HIV-1 integrase catalytic core and C-terminal domains: a model for viral DNA binding," Proceedings of the National Academy of Sciences of the United States of America, vol. 97, no. 15, pp. 8233-8238, 2000.

[32] M. Jaskolski, J. N. Alexandratos, G. Bujacz, and A. Wlodawer, "Piecing together the structure of retroviral integrase, an important target in AIDS therapy," FEBS Journal, vol. 276, no. 11, pp. 2926-2946, 2009.

[33] J. R. Huff, "HIV protease: a novel chemotherapeutic target for AIDS," Journal of Medicinal Chemistry, vol. 34, no. 8, pp. 2305-2314, 1991.

[34] M. A. Navia, P. M. D. Fitzgerald, B. M. McKeever et al., "Three-dimensional structure of aspartyl protease from human immunodeficiency virus HIV-1," Nature, vol. 337, no. 6208, pp. 615-620, 1989.

[35] A. Wlodawer and J. Vondrasek, "Inhibitors of HIV-1 protease: a major success of structure-assisted drug design," Annual Review of Biophysics and Biomolecular Structure, vol. 27, pp. 249-284, 1998.

[36] M. Miller, "The early years of retroviral protease crystal structures," Biopolymers, vol. 94, no. 4, pp. 521-529, 2010.

[37] F. Christ, A. Voet, A. Marchand et al., "Rational design of small-molecule inhibitors of the LEDGF/p75-integrase interaction and HIV replication," Nature Chemical Biology, vol. 6, no. 6, pp. 442-448, 2010.

[38] W. Thys, K. Bartholomeeusen, Z. Debyser, and J. De Rijck, "Cellular cofactors of HIV integration," in HIV-1 Integrase: Mechanism and Inhibitor Design, N. Neamati, Ed., pp. 105129, John Wiley \& Sons, Hoboken, NJ, USA, 2011.

[39] C. M. Farnet and F. D. Bushman, "HIV-1 cDNA integration: requirement of HMG $\mathrm{I}(\mathrm{Y})$ protein for function of preintegration complexes in vitro," Cell, vol. 88, no. 4, pp. 483-492, 1997.

[40] I. De Martino, R. Visone, M. Fedele et al., "Regulation of microRNA expression by HMGA1 proteins," Oncogene, vol. 28, no. 11, pp. 1432-1442, 2009.

[41] A. Fusco and M. Fedele, "Roles of HMGA proteins in cancer," Nature Reviews Cancer, vol. 7, no. 12, pp. 899-910, 2007.

[42] M. S. Lee and R. Craigie, "A previously unidentified host protein protects retroviral DNA from autointegration," Proceedings of the National Academy of Sciences of the United States of America, vol. 95, no. 4, pp. 1528-1533, 1998.

[43] C. W. Lin and A. Engelman, "The barrier-to-autointegration factor is a component of functional human immunodeficiency virus type 1 preintegration complexes," Journal of Virology, vol. 77, no. 8, pp. 5030-5036, 2003.

[44] Y. Suzuki and R. Craigie, "Regulatory mechanisms by which barrier-to-autointegration factor blocks autointegration and stimulates intermolecular integration of Moloney murine leukemia virus preintegration complexes," Journal of Virology, vol. 76, no. 23, pp. 12376-12380, 2002.

[45] M. C. Shun, J. E. Daigle, N. Vandegraaff, and A. Engelman, "Wild-type levels of human immunodeficiency virus type 1 infectivity in the absence of cellular emerin protein," Journal of Virology, vol. 81, no. 1, pp. 166-172, 2007.

[46] M. B. Feinberg and D. Trono, "Intracellular immunization: trans-dominant mutants of HIV gene products as tools for the study and interruption of viral replication," AIDS Research and Human Retroviruses, vol. 8, no. 6, pp. 10131022, 1992.

[47] D. Bevec, M. Dobrovnik, J. Hauber, and E. Bohnlein, "Inhibition of human immunodeficiency virus type 1 replication in human $\mathrm{T}$ cells by retroviral-mediated gene transfer of a dominant-negative Rev trans-activator," Proceedings of the National Academy of Sciences of the United States of America, vol. 89, no. 20, pp. 9870-9874, 1992.

[48] S. E. Liem, A. Ramezani, X. Li, and S. Joshi, "The development and testing of retroviral vectors expressing transdominant mutants of HIV-1 proteins to confer anti-HIV-1 resistance," Human Gene Therapy, vol. 4, no. 5, pp. 625-634, 1993.

[49] J. De Rijck, L. Vandekerckhove, R. Gijsbers et al., "Overexpression of the lens epithelium-derived growth factor/p75 integrase binding domain inhibits human immunodeficiency virus replication," Journal of Virology, vol. 80, no. 23, pp. 11498-11509, 2006. 
[50] M. Llano, D. T. Saenz, A. Meehan et al., "An essential role for LEDGF/p75 in HIV integration," Science, vol. 314, no. 5798, pp. 461-464, 2006.

[51] T. M. Murali, M. D. Dyer, D. Badger, B. M. Tyler, and M. G. Katze, "Network-based prediction and analysis of HIV dependency factors," PLoS Computational Biology, vol. 7, no. 9, pp. e1002164-e1002178, 2011.

[52] J. C. Rain, A. Cribier, A. Gérard, S. Emiliani, and R. Benarous, "Yeast two-hybrid detection of integrase-host factor interactions," Methods, vol. 47, no. 4, pp. 291-297, 2009.

[53] G. V. Kalpana, S. Marmon, W. Wang, G. R. Crabtree, and S. P. Goff, "Binding and stimulation of HIV-1 integrase by a human homolog of yeast transcription factor SNF5," Science, vol. 266, no. 5193, pp. 2002-2006, 1994.

[54] F. Christ, W. Thys, J. De Rijck et al., "Transportin-SR2 Imports HIV into the Nucleus," Current Biology, vol. 18, no. 16 , pp. 1192-1202, 2008.

[55] A. L. Brass, D. M. Dykxhoorn, Y. Benita et al., "Identification of host proteins required for HIV infection through a functional genomicscreen," Science, vol. 319, no. 5865, pp. 921-926, 2008.

[56] H. Zhou, M. Xu, Q. Huang et al., "Genome-scale RNAi screen for host factors required for HIV replication," Cell Host and Microbe, vol. 4, no. 5, pp. 495-504, 2008.

[57] F. D. Bushman, N. Malani, J. Fernandes et al., "Host cell factors in HIV replication: meta-analysis of genome-wide studies," PLoS Pathogens, vol. 5, no. 5, Article ID e1000437, 2009.

[58] W. Thys, S. De Houwer, J. Demeulemeester et al., "Interplay between HIV entry and transportin-SR2 dependency," Retrovirology, vol. 8, article 7, 2011.

[59] S. A. Adam, R. Sterne-Marr, and L. Gerace, "Chapter 18 in vitro nuclear protein import using permeabilized mammalian cells," Methods in Cell Biology, vol. 35, pp. 469482, 1991.

[60] C. Marshallsay and R. Luhrmann, "In vitro nuclear import of snRNPs: cytosolic factors mediate $\mathrm{m} 3 \mathrm{G}$-cap dependence of U1 and U2 snRNP transport," EMBO Journal, vol. 13, no. 1, pp. 222-231, 1994.

[61] J. E. Hagstrom, J. J. Ludtke, M. C. Bassik, M. G. Sebestyén, S. A. Adam, and J. A. Wolff, "Nuclear import of DNA in digitonin-permeabilized cells," Journal of Cell Science, vol. 110, no. 18, pp. 2323-2331, 1997.

[62] D. McDonald, M. A. Vodicka, G. Lucero et al., "Visualization of the intracellular behavior of HIV in living cells," Journal of Cell Biology, vol. 159, no. 3, pp. 441-452, 2002.

[63] N. Arhel, A. Genovesio, K. A. Kim et al., "Quantitative four-dimensional tracking of cytoplasmic and nuclear HIV1 complexes," Nature Methods, vol. 3, no. 10, pp. 817-824, 2006.

[64] B. Müller, "Novel imaging technologies in the study of HIV," Future Virology, vol. 6, no. 8, pp. 929-940, 2011.

[65] A. Albanese, D. Arosio, M. Terreni, and A. Cereseto, "HIV1 pre-integration complexes selectively target decondensed chromatin in the nuclear periphery," PLOS ONE, vol. 3, no. 6, Article ID e2413, 2008.

[66] X. Wu, H. Liu, H. Xiao et al., "Targeting foreign proteins to human immunodeficiency virus particles via fusion with $\mathrm{Vpr}$ and Vpx," Journal of Virology, vol. 69, no. 6, pp. 3389-3398, 1995.

[67] P. Colas, "High-throughput screening assays to discover small-molecule inhibitors of protein interactions," Current Drug Discovery Technologies, vol. 5, no. 3, pp. 190-199, 2008.
[68] L. M. Mayr and D. Bojanic, "Novel trends in highthroughput screening," Current Opinion in Pharmacology, vol. 9, no. 5, pp. 580-588, 2009.

[69] M. A. Cooper, "Optical biosensors: where next and how soon?” Drug Discovery Today, vol. 11, no. 23-24, pp. 10611067,2006

[70] Y. Izumoto, T. Kuroda, H. Harada, T. Kishimoto, and H. Nakamura, "Hepatoma-derived growth factor belongs to a gene family in mice showing significant homology in the amino terminus," Biochemical and Biophysical Research Communications, vol. 238, no. 1, pp. 26-32, 1997.

[71] F. Dietz, S. Franken, K. Yoshida, H. Nakamura, J. Kappler, and V. Gieselmann, "The family of hepatoma-derived growth factor proteins: characterization of a new member HRP-4 and classification of its subfamilies," Biochemical Journal, vol. 366, no. 2, pp. 491-500, 2002.

[72] G. Maertens, P. Cherepanov, W. Pluymers et al., "LEDGF/p75 is essential for nuclear and chromosomal targeting of HIV-1 integrase in human cells," Journal of Biological Chemistry, vol. 278, no. 35, pp. 33528-33539, 2003.

[73] A. Ciuffi, M. Llano, E. Poeschla et al., "A role for LEDGF/p75 in targeting HIV DNA integration," Nature Medicine, vol. 11, no. 12, pp. 1287-1289, 2005.

[74] M. C. Shun, N. K. Raghavendra, N. Vandegraaff et al., "LEDGF/p75 functions downstream from preintegration complex formation to effect gene-specific HIV-1 integration," Genes and Development, vol. 21, no. 14, pp. 1767-1778, 2007.

[75] H. M. Marshall, K. Ronen, C. Berry et al., "Role of PSIP 1/LEDGF/p75 in lentiviral infectivity and integration targeting," PLoS ONE, vol. 2, no. 12, Article ID e1340, 2007.

[76] J. Hendrix, R. Gijsbers, J. De Rijck et al., "The transcriptional co-activator LEDGF/p75 displays a dynamic scan-and-lock mechanism for chromatin tethering," Nucleic Acids Research, vol. 39, no. 4, pp. 1310-1325, 2011.

[77] P. Cherepanov, E. Devroe, P. A. Silver, and A. Engelman, "Identification of an evolutionarily conserved domain in human lens epithelium-derived growth factor/transcriptional co-activator p75 (LEDGF/p75) that binds HIV-1 integrase," Journal of Biological Chemistry, vol. 279, no. 47, pp. 48883-48892, 2004.

[78] M. Llano, S. Delgado, M. Vanegas, and E. M. Poeschla, "Lens epithelium-derived growth factor/p75 prevents proteasomal degradation of HIV-1 integrase," Journal of Biological Chemistry, vol. 279, no. 53, pp. 55570-55577, 2004.

[79] E. M. Poeschla, "Integrase, LEDGF/p75 and HIV replication," Cellular and Molecular Life Sciences, vol. 65, no. 9, pp. 14031424, 2008.

[80] A. Engelman and P. Cherepanov, "The lentiviral integrase binding protein LEDGF/p75 and HIV-1 replication," PLoS Pathogens, vol. 4, no. 3, Article ID e1000046, 2008.

[81] S. Emiliani, A. Mousnier, K. Busschots et al., "Integrase mutants defective for interaction with LEDGF/p75 are impaired in chromosome tethering and HIV-1 replication," Journal of Biological Chemistry, vol. 280, no. 27, pp. 2551725523, 2005.

[82] L. Vandekerckhove, F. Christ, B. Van Maele et al., "Transient and stable knockdown of the integrase cofactor LEDGF/p75 reveals its role in the replication cycle of human immunodeficiency virus," Journal of Virology, vol. 80, no. 4, pp. 18861896, 2006.

[83] P. Cherepanov, Z. Y. J. Sun, S. Rahman, G. Maertens, G. Wagner, and A. Engelman, "Solution structure of the HIV-1 
integrase-binding domain in LEDGF/p75," Nature Structural and Molecular Biology, vol. 12, no. 6, pp. 526-532, 2005.

[84] P. Cherepanov, A. L. B. Ambrosio, S. Rahman, T. Ellenberger, and A. Engelman, "Structural basis for the recognition between HIV-1 integrase and transcriptional coactivator p75," Proceedings of the National Academy of Sciences of the United States of America, vol. 102, no. 48, pp. 17308-17313, 2005.

[85] K. Busschots, A. Voet, M. De Maeyer et al., "Identification of the LEDGF/p75 binding site in HIV-1 integrase," Journal of Molecular Biology, vol. 365, no. 5, pp. 1480-1492, 2007.

[86] L. Q. Al-Mawsawi, F. Christ, R. Dayam, Z. Debyser, and N. Neamati, "Inhibitory profile of a LEDGF/p75 peptide against HIV-1 integrase: insight into integrase-DNA complex formation and catalysis," FEBS Letters, vol. 582, no. 10, pp. 1425-1430, 2008.

[87] L. Du, Y. Zhao, J. Chen et al., "D77, one benzoic acid derivative, functions as a novel anti-HIV-1 inhibitor targeting the interaction between integrase and cellular LEDGF/p75," Biochemical and Biophysical Research Communications, vol. 375, no. 1, pp. 139-144, 2008.

[88] L. De Luca, M. L. Barreca, S. Ferro et al., "Pharmacophorebased discovery of small-molecule inhibitors of proteinprotein interactions between HIV-1 integrase and cellular cofactor LEDGF/p75," ChemMedChem, vol. 4, no. 8, pp. 1311-1316, 2009.

[89] K. Bartholomeeusen, J. De Rijck, K. Busschots et al., "Differential interaction of HIV-1 integrase and JPO2 with the C terminus of LEDGF/p75," Journal of Molecular Biology, vol. 372, no. 2, pp. 407-421, 2007.

[90] K. Bartholomeeusen, F. Christ, J. Hendrix et al., "Lens epithelium-derived growth factor/p75 interacts with the transposase-derived DDE domain of pogZ," Journal of Biological Chemistry, vol. 284, no. 17, pp. 11467-11477, 2009.

[91] G. N. Maertens, P. Cherepanov, and A. Engelman, "Transcriptional co-activator p75 binds and tethers the Mycinteracting protein JPO2 to chromatin," Journal of Cell Science, vol. 119, no. 12, pp. 2563-2571, 2006.

[92] S. Hughes, V. Jenkins, M. J. Dar, A. Engelman, and P. Cherepanov, "Transcriptional co-activator LEDGF interacts with Cdc7-activator of S-phase kinase (ASK) and stimulates its enzymatic activity," Journal of Biological Chemistry, vol. 285, no. 1, pp. 541-554, 2010.

[93] A. Yokoyama and M. L. Cleary, "Menin critically links MLL proteins with LEDGF on cancer-associated target genes," Cancer Cell, vol. 14, no. 1, pp. 36-46, 2008.

[94] J. Huang, B. Gurung, B. Wan et al., "The same pocket in menin binds both MLL and JUND but has opposite effects on transcription," Nature, vol. 482, no. 7386, pp. 542-546, 2012.

[95] Y. Hou, D. E. McGuinness, A. J. Prongay et al., "Screening for antiviral inhibitors of the HIV integrase-LEDGF/p75 interaction using the AlphaScreen luminescent proximity assay," Journal of Biomolecular Screening, vol. 13, no. 5, pp. 406-414, 2008.

[96] S. Maignan, J.-P. Guilloteau, Q. Zhou-Liu, C. Clément-Mella, and V. Mikol, "Crystal structures of the catalytic domain of HIV-1 integrase free and complexed with its metal cofactor: high level of similarity of the active site with other viral integrases," Journal of Molecular Biology, vol. 282, no. 2, pp. 359-368, 1998.

[97] V. Molteni, J. Greenwald, D. Rhodes et al., "Identification of a small-molecule binding site at the dimer interface of the HIV integrase catalytic domain," Acta Crystallographica Section D, vol. 57, no. 4, pp. 536-544, 2001.

[98] D. J. Hazuda, P. Felock, M. Witmer et al., "Inhibitors of strand transfer that prevent integration and inhibit HIV-1 replication in cells," Science, vol. 287, no. 5453, pp. 646-650, 2000.

[99] R. Schrijvers, J. De Rijck, J. Demeulemeester et al., "LEDGF/p75-independent HIV-1 replication demonstrates a role for HRP-2 and remains sensitive to inhibition by LEDGINs," PLoS Pathogens, vol. 8, no. 3, pp. e1002558e1002574, 2012.

[100] O. Delelis, I. Malet, L. Na et al., "The G140S mutation in HIV integrases from raltegravir-resistant patients rescues catalytic defect due to the resistance Q148H mutation," Nucleic Acids Research, vol. 37, no. 4, pp. 1193-1201, 2009.

[101] T. Roe, T. C. Reynolds, G. Yu, and P. O. Brown, "Integration of murine leukemia virus DNA depends on mitosis," EMBO Journal, vol. 12, no. 5, pp. 2099-2108, 1993.

[102] P. F. Lewis and M. Emerman, "Passage through mitosis is required for oncoretroviruses but not for the human immunodeficiency virus," Journal of Virology, vol. 68, no. 1, pp. 510-516, 1994.

[103] M. I. Bukrinsky, N. Sharova, M. P. Dempsey et al., "Active nuclear import of human immunodeficiency virus type 1 preintegration complexes," Proceedings of the National Academy of Sciences of the United States of America, vol. 89, no. 14, pp. 6580-6584, 1992.

[104] Y. Suzuki and R. Craigie, "The road to chromatin-nuclear entry of retroviruses," Nature Reviews Microbiology, vol. 5, no. 3, pp. 187-196, 2007.

[105] J. De Rijck, L. Vandekerckhove, F. Christ, and Z. Debyser, "Lentiviral nuclear import: a complex interplay between virus and host," BioEssays, vol. 29, no. 5, pp. 441-451, 2007.

[106] V. Zennou, C. Petit, D. Guetard, U. Nerhbass, L. Montagnier, and P. Charneau, "HIV-1 genome nuclear import is mediated by a central DNA flap," Cell, vol. 101, no. 2, pp. 173-185, 2000.

[107] A. Sirven, F. Pflumio, V. Zennou et al., "The human immunodeficiency virus type-1 central DNA flap is a crucial determinant for lentiviral vector nuclear import and gene transduction of human hematopoietic stem cells," Blood, vol. 96, no. 13, pp. 4103-4110, 2000.

[108] J. De Rijck and Z. Debyser, "The central DNA flap of the human immunodeficiency virus type 1 is important for viral replication," Biochemical and Biophysical Research Communications, vol. 349, no. 3, pp. 1100-1110, 2006.

[109] M. Yamashita and M. Emerman, "Retroviral infection of non-dividing cells: old and new perspectives," Virology, vol. 344, no. 1, pp. 88-93, 2006.

[110] M. Yamashita and M. Emerman, "The cell cycle independence of HIV infections is not determined by known karyophilic viral elements," PLoS Pathogens, vol. 1, no. 3, Article ID e18, 2005.

[111] B. Van Maele, J. De Rijck, E. De Clercq, and Z. Debyser, "Impact of the central polypurine tract on the kinetics of human immunodeficiency virus type 1 vector transduction," Journal of Virology, vol. 77, no. 8, pp. 4685-4694, 2003.

[112] L. Rivière, J. L. Darlix, and A. Cimarelli, "Analysis of the viral elements required in the nuclear import of HIV-1 DNA," Journal of Virology, vol. 84, no. 2, pp. 729-739, 2010.

[113] M. Yamashita and M. Emerman, "Capsid is a dominant determinant of retrovirus infectivity in nondividing cells," Journal of Virology, vol. 78, no. 11, pp. 5670-5678, 2004. 
[114] M. Yamashita, O. Perez, T. J. Hope, and M. Emerman, "Evidence for direct involvement of the capsid protein in HIV infection of nondividing cells," PLoS Pathogens, vol. 3, no. 10, Article ID e156, 2007.

[115] T. Schaller, K. E. Ocwieja, J. Rasaiyaah et al., "HIV-1 capsid-cyclophilin interactions determine nuclear import pathway, integration targeting and replication efficiency," PLoS Pathogens, vol. 7, no. 12, pp. e1002439-e1002453, 2011.

[116] P. Gallay, V. Stitt, C. Mundy, M. Oettinger, and D. Trono, "Role of the karyopherin pathway in human immunodeficiency virus type 1 nuclear import," Journal of Virology, vol. 70, no. 2, pp. 1027-1032, 1996.

[117] P. Gallay, T. Hope, D. Chin, and D. Trono, "HIV-1 infection of nondividing cells through the recognition of integrase by the importin/karyopherin pathway," Proceedings of the National Academy of Sciences of the United States of America, vol. 94, no. 18, pp. 9825-9830, 1997.

[118] O. K. Haffar, S. Popov, L. Dubrovsky et al., "Two nuclear localization signals in the HIV-1 matrix protein regulate nuclear import of the HIV-1 pre-integration complex," Journal of Molecular Biology, vol. 299, no. 2, pp. 359-368, 2000.

[119] A. C. Hearps and D. A. Jans, "HIV-1 integrase is capable of targeting DNA to the nucleus via an importin $\alpha / \beta$-dependent mechanism," Biochemical Journal, vol. 398, no. 3, pp. 475484, 2006.

[120] Z. Ao, K. D. Jayappa, B. Wang et al., "Importin $\alpha 3$ interacts with HIV-1 integrase and contributes to HIV-1 nuclear import and replication," Journal of Virology, vol. 84, no. 17, pp. 8650-8663, 2010.

[121] K. D. Jayappa, Z. Ao, M. Yang, J. Wang, and X. Yao, "Identification of critical motifs within HIV-1 integrase required for importin $\alpha 3$ interaction and viral cDNA nuclear import," Journal of Molecular Biology, vol. 410, no. 5, pp. 847$862,2011$.

[122] A. Fassati, D. Görlich, I. Harrison, L. Zaytseva, and J. M. Mingot, "Nuclear import of HIV-1 intracellular reverse transcription complexes is mediated by importin 7," EMBO Journal, vol. 22, no. 14, pp. 3675-3685, 2003.

[123] Z. Ao, G. Huang, H. Yao et al., "Interaction of human immunodeficiency virus type 1 integrase with cellular nuclear import receptor importin 7 and its impact on viral replication," Journal of Biological Chemistry, vol. 282, no. 18, pp. 13456-13467, 2007.

[124] C. L. Woodward, S. Prakobwanakit, S. Mosessian, and S. A. Chow, "Integrase interacts with nucleoporin NUP153 to mediate the nuclear import of human immunodeficiency virus type 1," Journal of Virology, vol. 83, no. 13, pp. 65226533, 2009.

[125] K. Lee, Z. Ambrose, T. D. Martin et al., "Flexible use of nuclear import pathways by HIV-1," Cell Host and Microbe, vol. 7, no. 3, pp. 221-233, 2010.

[126] P. Varadarajan, S. Mahalingam, P. Liu et al., "The functionally conserved nucleoporins Nup124p from fission yeast and the human Nup153 mediate nuclear import and activity of the Tf1 retrotransposon and HIV-1 Vpr," Molecular Biology of the Cell, vol. 16, no. 4, pp. 1823-1838, 2005.

[127] K. A. Matreyek and A. Engelman, "The requirement for nucleoporin NUP153 during human immunodeficiency virus type 1 infection is determined by the viral capsid," Journal of Virology, vol. 85, no. 15, pp. 7818-7827, 2011.

[128] Z. Ao, K. Danappa Jayappa, B. Wang et al., "Contribution of host nucleoporin 62 in HIV-1 integrase chromatin association and viral DNA integration," Journal of Biological Chemistry, vol. 287, no. 13, pp. 10544-10555, 2012.

[129] S. Popov, M. Rexach, L. Ratner, G. Blobel, and M. Bukrinsky, "Viral protein R regulates docking of the HIV-1 preintegration complex to the nuclear pore complex," Journal of Biological Chemistry, vol. 273, no. 21, pp. 13347-13352, 1998.

[130] K.-H. Kok, T. Lei, and D.-Y. Jin, "SiRNA and shRNA screens advance key understanding of host factors required for HIV1 replication," Retrovirology, vol. 6, article 78, 2009.

[131] H. Ebina, J. Aoki, S. Hatta, T. Yoshida, and Y. Koyanagi, "Role of Nup98 in nuclear entry of human immunodeficiency virus type 1 cDNA," Microbes and Infection, vol. 6, no. 8, pp. 715724, 2004.

[132] M. L. Yeung, L. Houzet, V. S. R. K. Yedavalli, and K. T. Jeang, "A genome-wide short hairpin RNA screening of Jurkat Tcells for human proteins contributing to productive HIV-1 replication," Journal of Biological Chemistry, vol. 284, no. 29, pp. 19463-19473, 2009.

[133] S. Hutten, S. Wälde, C. Spillner, J. Hauber, and R. H. Kehlenbach, "The nuclear pore component Nup358 promotes transportin-dependent nuclear import," Journal of Cell Science, vol. 122, no. 8, pp. 1100-1110, 2009.

[134] K. E. Ocwieja, T. L. Brady, K. Ronen et al., "HIV integration targeting: a pathway involving transportin-3 and the nuclear pore protein RanBP2," PLoS Pathogens, vol. 7, no. 3, Article ID e1001313, 2011.

[135] A. Armon-Omer, A. Graessmann, and A. Loyter, "A synthetic peptide bearing the HIV-1 integrase 161-173 amino acid residues mediates active nuclear import and binding to importin $\alpha$ : characterization of a functional nuclear localization signal," Journal of Molecular Biology, vol. 336, no. 5, pp. 1117-1128, 2004.

[136] M. Köhler, C. Speck, M. Christiansen et al., "Evidence for distinct substrate specificities of importin $\alpha$ family members in nuclear protein import," Molecular and Cellular Biology, vol. 19, no. 11, pp. 7782-7791, 1999.

[137] C. Depienne, A. Mousnier, H. Leh et al., "Characterization of the nuclear import pathway for HIV-1 integrase," Journal of Biological Chemistry, vol. 276, no. 21, pp. 18102-18107, 2001.

[138] S. P. Zielske and M. Stevenson, "Importin 7 may be dispensable for human immunodeficiency virus type 1 and simian immunodeficiency virus infection of primary macrophages," Journal of Virology, vol. 79, no. 17, pp. 11541-11546, 2005.

[139] L. Zaitseva, P. Cherepanov, L. Leyens, S. J. Wilson, J. Rasaiyaah, and A. Fassati, "HIV-1 exploits importin 7 to maximize nuclear import of its DNA genome," Retrovirology, vol. 6, article 11, 2009.

[140] A. Monette, L. Ajamian, M. López-Lastra, and A. J. Mouland, "Human immunodeficiency virus type 1 (HIV-1) induces the cytoplasmic retention of heterogeneous nuclear ribonucleoprotein A1 by disrupting nuclear import. Implications for HIV-1 gene expression," Journal of Biological Chemistry, vol. 284, no. 45, pp. 31350-31362, 2009.

[141] A. Monette, N. Panté, and A. J. Mouland, "HIV-1 remodels the nuclear pore complex," Journal of Cell Biology, vol. 193, no. 4, pp. 619-631, 2011.

[142] T. Brady, L. M. Agosto, N. Malani, C. C. Berry, U. O’Doherty, and F. Bushman, "HIV integration site distributions in resting and activated $\mathrm{CD}^{4+} \mathrm{T}$ cells infected in culture," AIDS, vol. 23, no. 12, pp. 1461-1471, 2009.

[143] R. Zhang, R. Mehla, and A. Chauhan, "Perturbation of host nuclear membrane component RanBP2 impairs the nuclear import of human immunodeficiency virus -1 preintegration 
complex (DNA)," PLoS ONE, vol. 5, no. 12, Article ID e15620, 2010.

[144] M. C. Lai, R. I. Lin, S. Y. Huang, C. W. Tsai, and W. Y. Tarn, "A human importin- $\beta$ family protein, transportin-SR2, interacts with the phosphorylated RS domain of SR proteins," Journal of Biological Chemistry, vol. 275, no. 11, pp. 7950-7957, 2000.

[145] N. Kataoka, J. L. Bachorik, and G. Dreyfuss, "TransportinSR, a nuclear import receptor for SR proteins," Journal of Cell Biology, vol. 145, no. 6, pp. 1145-1152, 1999.

[146] M. C. Lai, R. I. Lin, and W. Y. Tarn, "Transportin-SR2 mediates nuclear import of phosphorylated SR proteins," Proceedings of the National Academy of Sciences of the United States of America, vol. 98, no. 18, pp. 10154-10159, 2001.

[147] M. C. Lai, H. W. Kuo, W. C. Chang, and W. Y. Tarn, "A novel splicing regulator shares a nuclear import pathway with SR proteins," EMBO Journal, vol. 22, no. 6, pp. 1359-1369, 2003.

[148] S. Anguissola, W. J. McCormack, M. A. Morrin, W. J. Higgins, D. M. Fox, and D. M. Worrall, "Pigment Epithelium-Derived Factor (PEDF) Interacts with Transportin SR2, and Active Nuclear Import Is Facilitated by a Novel Nuclear Localization Motif," PLoS ONE, vol. 6, no. 10, pp. e26234-e26244, 2011.

[149] M. L. Hedley, H. Amrein, and T. Maniatis, "An amino acid sequence motif sufficient for subnuclear localization of an arginine/serine-rich splicing factor," Proceedings of the National Academy of Sciences of the United States of America, vol. 92, no. 25, pp. 11524-11528, 1995.

[150] J. F. Cáceres, T. Misteli, G. R. Screaton, D. L. Spector, and A. R. Krainer, "Role of the modular domains of SR proteins in subnuclear localization and alternative splicing specificity," Journal of Cell Biology, vol. 138, no. 2, pp. 225-238, 1997.

[151] M. Stewart, "Molecular mechanism of the nuclear protein import cycle," Nature Reviews Molecular Cell Biology, vol. 8, no. 3, pp. 195-208, 2007.

[152] M. Caputi, M. Freund, S. Kammler, C. Asang, and H. Schaal, "A bidirectional SF2/ASF- and SRp40-dependent splicing enhancer regulates human immunodeficiency virus type 1 rev, env, vpu, and nef gene expression," Journal of Virology, vol. 78, no. 12, pp. 6517-6526, 2004.

[153] S. Jacquenet, D. Decimo, D. Muriaux, and J. L. Darlix, "Dual effect of the SR proteins ASF/SF2, SC35 and 9G8 on HIV-1 RNA splicing and virion production," Retrovirology, vol. 2, article 33, 2005.

[154] L. Krishnan, K. A. Matreyek, I. Oztop et al., “The requirement for cellular transportin 3 (TNPO3 or TRN-SR2) during infection maps to human immunodeficiency virus type 1 capsid and not integrase," Journal of Virology, vol. 84, no. 1, pp. 397-406, 2010.

[155] A. De Iaco and J. Luban, "Inhibition of HIV-1 infection by TNPO3 depletion is determined by capsid and detectable after viral cDNA enters the nucleus," Retrovirology, vol. 8, pp. 98-116, 2011.

[156] E. C. Logue, K. T. Taylor, P. H. Goff, and N. R. Landau, "The cargo-binding domain of transportin 3 is required for lentivirus nuclear import," Journal of Virology, vol. 85, no. 24, pp. 12950-12961, 2011.

[157] D. Yu, W. Wang, A. Yoder, M. Spear, and Y. Wu, "The HIV envelope but not VSV glycoprotein is capable of mediating HIV latent infection of resting CD4 T cells," PLoS Pathogens, vol. 5, no. 10, Article ID e1000633, 2009.

[158] A. Cribier, E. Segeral, O. Delelis et al., "Mutations affecting interaction of integrase with TNPO3 do not prevent HIV-1 cDNA nuclear import," Retrovirology, vol. 8, no. 1, pp. 104117, 2011.
[159] L. Zhou, E. Sokolskaja, C. Jolly, W. James, S. A. Cowley, and A. Fassati, "Transportin 3 promotes a nuclear maturation step required for efficient HIV-1 integration," PLoS Pathogens, vol. 7, no. 8, pp. e1002194-e1002212, 2011. 

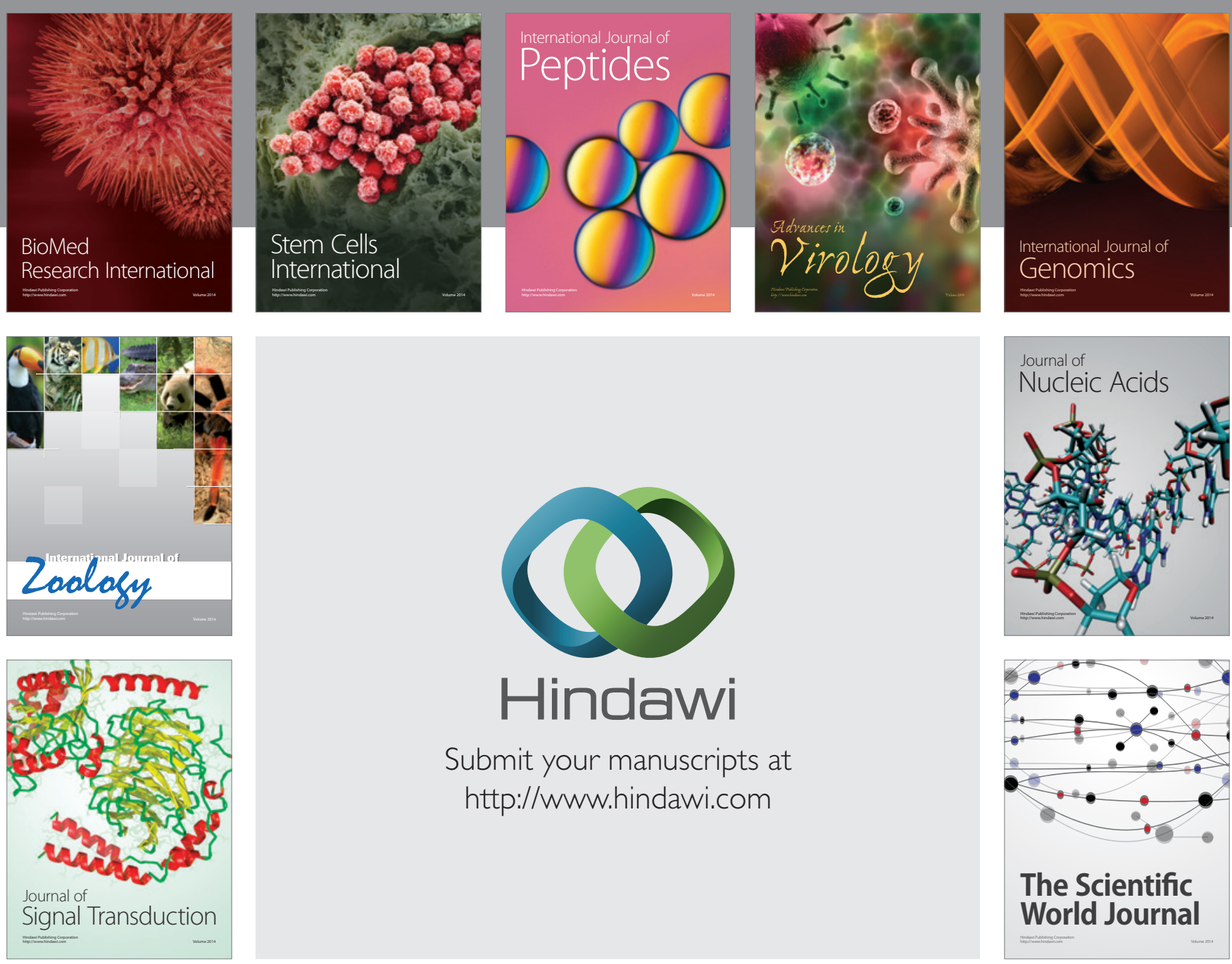

Submit your manuscripts at

http://www.hindawi.com
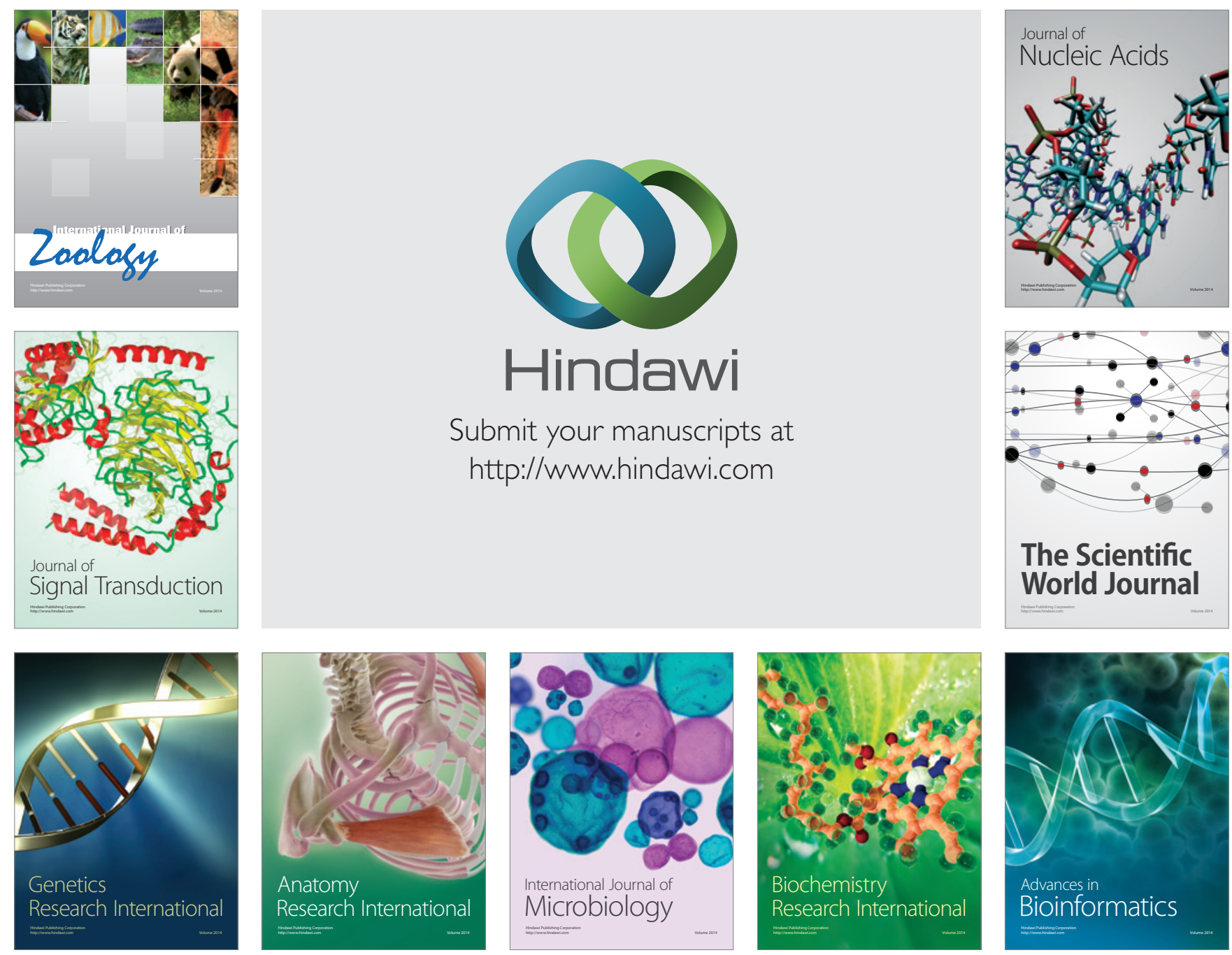

The Scientific World Journal
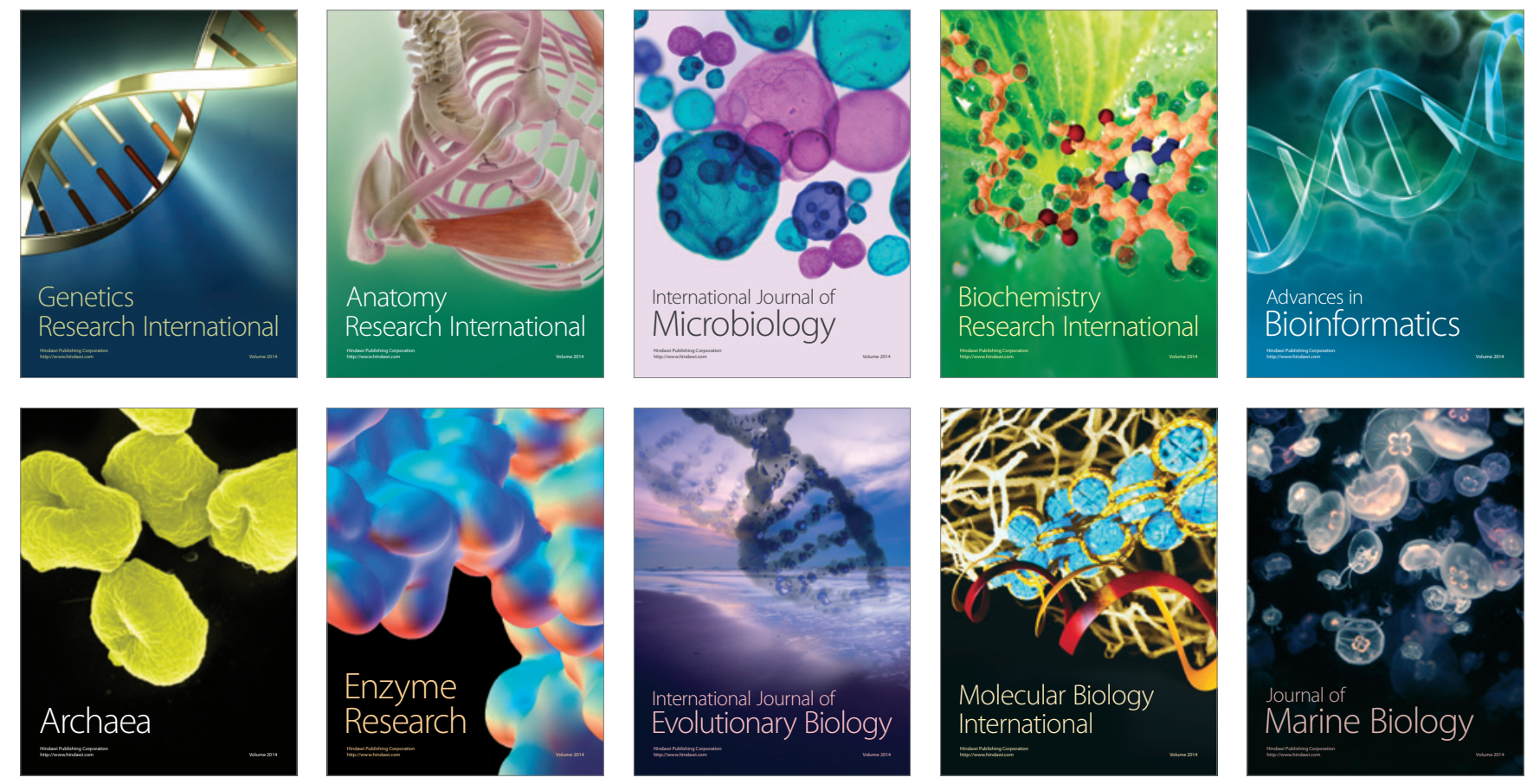